\title{
Quantification of $\mathrm{O}_{2}$ formation during UV photolysis of water ice: $\mathrm{H}_{2} \mathrm{O}$ and $\mathrm{H}_{2} \mathrm{O}: \mathrm{CO}_{2}$ ices
}

\author{
M. Bulak ${ }^{1}$, D. M. Paardekooper ${ }^{1}$, G. Fedoseev ${ }^{1,2}$, K.-J. Chuang ${ }^{1}$, J. Terwisscha van Scheltinga ${ }^{1}$, \\ C. Eistrup ${ }^{3}$, and H. Linnartz ${ }^{1}$ \\ ${ }^{1}$ Laboratory for Astrophysics, Leiden Observatory, Leiden University, PO Box 9513, 2300 RA Leiden, The Netherlands \\ e-mail: bulak@strw.leidenuniv.nl \\ 2 Research Laboratory for Astrochemistry, Ural Federal University, Kuibysheva St. 48, 620026 Ekaterinburg, Russia \\ ${ }^{3}$ Max Planck Institute for Astronomy, Königstuhl 17, 69117 Heidelberg, Germany
}

Received 26 July 2021 / Accepted 30 August 2021

\begin{abstract}
Context. The Rosetta and Giotto missions investigated the composition of the cometary comae of 67P/Churyumov-Gerasimenko and 1P/Halley, respectively. In both cases, a surprisingly large amount of molecular oxygen $\left(\mathrm{O}_{2}\right)$ was detected and was well correlated with the observed abundances of $\mathrm{H}_{2} \mathrm{O}$. Laboratory experiments simulating chemical processing for various astronomical environments already showed that formation of solid state $\mathrm{O}_{2}$ is linked to water. However, a quantitative study of $\mathrm{O}_{2}$ formation upon UV photolysis of pure $\mathrm{H}_{2} \mathrm{O}$ and $\mathrm{H}_{2} \mathrm{O}$ dominated interstellar ice analogues is still missing.

Aims. The goal of this work is to investigate whether the UV irradiation of $\mathrm{H}_{2} \mathrm{O}$-rich ice produced at the earliest stages of star formation is efficient enough to explain the observed abundance of cometary $\mathrm{O}_{2}$.

Methods. The photochemistry of pure $\mathrm{H}_{2}{ }^{16} \mathrm{O}\left(\mathrm{H}_{2}{ }^{18} \mathrm{O}\right.$ ) as well as mixed $\mathrm{H}_{2} \mathrm{O}: \mathrm{CO}_{2}$ (ratio of 100:11, 100:22, 100:44) and $\mathrm{H}_{2} \mathrm{O}: \mathrm{CO}_{2}: \mathrm{O}_{2}$ $(100: 22: 2)$ ices was quantified during UV photolysis. Laser desorption post-ionisation time of flight mass spectrometry (LDPI TOF MS) was used to probe molecular abundances in the ice as a function of UV fluence.

Results. Upon UV photolysis of pure amorphous $\mathrm{H}_{2} \mathrm{O}$ ice, deposited at $20 \mathrm{~K}$, formation of $\mathrm{O}_{2}$ and $\mathrm{H}_{2} \mathrm{O}_{2}$ is observed at abundances of, respectively, $(0.9 \pm 0.2) \%\left(\mathrm{O}_{2} / \mathrm{H}_{2} \mathrm{O}\right)$ and $(1.3 \pm 0.3) \%\left(\mathrm{H}_{2} \mathrm{O}_{2} / \mathrm{H}_{2} \mathrm{O}\right)$. To the best of our knowledge, this is the first quantitative characterisation of the kinetics of this process. During the UV photolysis of mixed $\mathrm{H}_{2} \mathrm{O}: \mathrm{CO}_{2}$ ices, the formation of the relative amount of $\mathrm{O}_{2}$ compared to $\mathrm{H}_{2} \mathrm{O}$ increases to a level of $(1.6 \pm 0.4) \%$ (for $\mathrm{H}_{2} \mathrm{O}: \mathrm{CO}_{2}$ ratio of 100:22), while the $\left(\mathrm{H}_{2} \mathrm{O}_{2} / \mathrm{H}_{2} \mathrm{O}\right.$ ) yield remains similar to experiments with pure water. In an ice enriched with $\mathrm{O}_{2}(2 \%)$, the $\mathrm{O}_{2}$ level increases up to $7 \%$ with regard to $\mathrm{H}_{2} \mathrm{O}$, at low UV fluence, which is higher than expected on the basis of the enrichment alone. The resulting $\mathrm{O}_{2} / \mathrm{H}_{2} \mathrm{O}$ values derived for the $\mathrm{H}_{2} \mathrm{O}$ and $\mathrm{H}_{2} \mathrm{O}: \mathrm{CO}_{2}$ ices may account for a (substantial) part of the high oxygen amounts found in the comae of 67P and $1 \mathrm{P}$.
\end{abstract}

Key words. astrochemistry - molecular processes - methods: laboratory: solid state comets: individual: 67P/Churyumov-Gerasimenko - comets: individual: 1P/Halley - ISM: molecules

\section{Introduction}

A major development in observations of $\mathrm{O}_{2}$ beyond our Earth was made in 2015 with the Rosetta space mission (Bieler et al. 2015). The composition of the cometary coma of 67P/Churyumov-Gerasimenko (67P) was measured utilising mass spectrometry. A relatively large amount of $\mathrm{O}_{2}$ was detected with its abundance well correlated with $\mathrm{H}_{2} \mathrm{O}$. The average concentration of $\mathrm{O}_{2} / \mathrm{H}_{2} \mathrm{O}$ in the ice was determined as $(3.1 \pm 1.1) \%$, well above the expected gas-phase ratio in the interstellar medium (ISM) (Woodall et al. 2007; Y1ld1z et al. 2013). Motivated by this detection, data collected by the Giotto mission, which measured the composition of the cometary coma of 1P/Halley (1P), was re-analysed. As a result, an average concentration of $\mathrm{O}_{2} / \mathrm{H}_{2} \mathrm{O}$ in $1 \mathrm{P}$ was derived at $(3.7 \pm 1.7) \%$ (Rubin et al. 2015).

Following these findings, a number of hypotheses have been proposed to explain the unexpectedly high $\mathrm{O}_{2}$ comet abundances and its scaling with $\mathrm{H}_{2} \mathrm{O}$. Among different scenarios reviewed by Luspay-Kuti et al. (2018), a primordial origin of $\mathrm{O}_{2}$ and $\mathrm{H}_{2} \mathrm{O}$ has been put forward, which is in agreement with the common origin of these dynamically different comets (Rubin et al. 2015). In the primordial scenario, the nuclei of comets are formed via the agglomeration of icy grains that formed during the dark molecular cloud stage or from more processed grains, frozen out during the protosolar nebula stage. In other words, the composition of the comet nuclei is expected to reflect, to a certain extent, the final composition of interstellar ices at the early stages of the star formation sequence.

Water is the main component of interstellar and cometary ices (Whittet et al. 1988; Bockelée-Morvan et al. 2000; Boogert et al. 2008). Solid $\mathrm{O}_{2}$ has not been detected because of its homo-nuclear diatomic nature, which turns the molecule nearly invisible in the infrared and millimetre-wavelength regime. As an alternative method, an infrared transition induced by $\mathrm{O}_{2}$ interacting with a surrounding matrix, could offer a detection, but was shown to be too weak for an astronomical identification (Müller et al. 2018). Hence, only generous upper limits of the $\mathrm{O}_{2} / \mathrm{H}_{2} \mathrm{O}$ ratio in the solid are available with values of $15 \%$ and $39 \%$, towards the low-mass protostar R CrA IRS2 and the massive protostar NGC 7538 IRS9, respectively (Vandenbussche et al. 1999). This is insufficient to test the hypothesis of a primordial origin of cometary $\mathrm{O}_{2}$.

Constraining observations of the gas-phase species provides a complimentary view of the involved gas-grain chemistry. In this case, however, it is important to note that the majority of 
water in the ISM resides in the ice, rather than in the gas. In addition, gas-phase chemistry as well as (non) thermal desorption mechanisms complicate the link between ice and gas. Despite low gas-phase abundances and challenging detection methods, a comparison of measured gas-phase abundances of $\mathrm{H}_{2} \mathrm{O}$ with respect to $\mathrm{O}_{2}$ has been made possible for $\rho$ Oph A (Larsson et al. 2007; Liseau et al. 2012; Larsson \& Liseau 2017). In the cold and dark regions of $\rho$ Oph A, the derived ratio of $\mathrm{O}_{2} / \mathrm{H}_{2} \mathrm{O}$ abundances reaches 10 , significantly varying from cometary measurements and further convoluting the understanding of $\mathrm{O}_{2}$ in the ice.

A different approach to investigate the link between $\mathrm{O}_{2}$ and $\mathrm{H}_{2} \mathrm{O}$ in solid state is with astrochemical modelling. Taquet et al. (2016) explored a grid of physical parameters which demonstrated that under specific dark cloud conditions, the resulting solid $\mathrm{O}_{2} / \mathrm{H}_{2} \mathrm{O}$ values and abundances of related species $\left(\mathrm{H}_{2} \mathrm{O}_{2}\right.$, $\mathrm{HO}_{2}$ ) could match the findings already cited here for 67P. In this model, the high $\mathrm{O}_{2} / \mathrm{H}_{2} \mathrm{O}$ value was a direct result of grain surface reactions at temperatures between 10 and $20 \mathrm{~K}$ and based on a formation pathway of $\mathrm{O}_{2}$ proceeding via recombination of $\mathrm{O}$ atoms (Tielens \& Hagen 1982; Cuppen et al. 2010). This reaction competes with the hydrogenation of $\mathrm{O}, \mathrm{O}_{2}$ or $\mathrm{O}_{3}$, which depletes most of the $\mathrm{O}$ and $\mathrm{O}_{2}$ reservoir and eventually leads to efficient formation of $\mathrm{H}_{2} \mathrm{O}$ (Ioppolo et al. 2008, 2010; Oba et al. 2009; Miyauchi et al. 2008; Lamberts et al. 2013). An alternative way of linking solid state $\mathrm{O}_{2}$ and $\mathrm{H}_{2} \mathrm{O}$ is through processing by various energetic particles - cosmic rays (CR), electrons, and UV photons. These processes play an important role in altering the solid state chemical reservoir in molecular clouds and protoplanetary discs. The energetic processing of $\mathrm{H}_{2} \mathrm{O}$-rich ice can result in the production of $\mathrm{O}_{2}$, as shown in a series of laboratory studies (e.g. Johnson 1991; Baragiola et al. 2002; Kimmel \& Orlando 1995; Öberg et al. 2009b). The final impact of each irradiation type depends on local parameters, including the density, ice thickness (related to penetration depth), and proximity of radiation sources.

Upon radiolysis of water ice, $\mathrm{H}_{2} \mathrm{O}$ molecules may desorb, ionise, or dissociate, with resulting transients reacting to form other products such as $\mathrm{O}_{2}, \mathrm{O}_{3}$ and $\mathrm{H}_{2} \mathrm{O}_{2}$ (Johnson \& Quickenden 1997). The observed conversion from $\mathrm{H}_{2} \mathrm{O}$ to $\mathrm{O}_{2}$ has been described with a simplified reaction: $2 \mathrm{H}_{2} \mathrm{O}$ (solid) $\rightarrow 2 \mathrm{H}_{2}$ (gas) $+\mathrm{O}_{2}$ (gas). The measured sputtered $\mathrm{O}_{2}$ yields (gas-phase) can vary across 4 orders of magnitude for different particles and energies, from $5 \times 10^{-7}$ to $5 \times 10^{-3}$ molecules $\mathrm{eV}^{-1}$ (e.g. Brown et al. 1982; Bar-Nun et al. 1985; see Teolis et al. 2017 for an overview).

The effects of electron bombardment of $\mathrm{H}_{2} \mathrm{O}$ and $\mathrm{D}_{2} \mathrm{O}$ ice have been previously studied by, for example, Sieger et al. (1998) and Zheng et al. (2006a). Based on these investigations, processing of water ice with different energy doses $(0$ $500 \mathrm{eV} \mathrm{molecule}^{-1}$ ) was found to result in the formation of $\mathrm{H}, \mathrm{O}$, $\mathrm{OH}, \mathrm{H}_{2}, \mathrm{O}_{2}$, and $\mathrm{H}_{2} \mathrm{O}_{2}$. Relatively higher yields of stable products were observed for amorphous water ice compared to crystalline ice (Zheng et al. 2007). Moreover, it was shown that the formation efficiency decreases with increasing ice temperature (12-90 K) (Zheng et al. 2006b).

The first study of UV photolysis of water ice demonstrated its photodesorption at temperatures between 35 and $100 \mathrm{~K}$ (Westley et al. 1995). Subsequently, Gerakines et al. (1996) showed that UV photolysis of $\mathrm{H}_{2} \mathrm{O}$ ice at $10 \mathrm{~K}$ also leads to formation of $\mathrm{OH}, \mathrm{H}_{2} \mathrm{O}_{2}$, and $\mathrm{HO}_{2}$. In addition, $\mathrm{UV}$ photolysis triggers amorphisation of the ice (Leto \& Baratta 2003). In the more recent studies focusing on the UV photodesorption of $\mathrm{H}_{2} \mathrm{O}$, $\mathrm{O}_{2}$ photodesorption was also detected, but it was not possible to derive its production yield in the solid state (Öberg et al. 2009b; Cruz-Diaz et al. 2018; Fillion et al. 2021). Additionally, the UVtriggered photodesorption and photochemistry of pure $\mathrm{O}_{2}$ ice was characterised (Zhen \& Linnartz 2014).

During the last few decades, the formation of $\mathrm{O}_{2}$ upon energetic processing of $\mathrm{H}_{2} \mathrm{O}$ ice has been strongly supported by experiments. However, the efficiency of this process and the involved chemical pathways remain under debate. As formation of $\mathrm{O}_{2}$ in the solid state cannot be measured by regular infrared (IR) spectroscopic techniques, to date, only the previously mentioned radiolysis experiments list quantitative yields on the $\mathrm{O}_{2}$ (gas) formation from water ice. These yields were measured with quadrupole mass spectrometry, which inherently measures an equilibrated gas-phase composition in the experimental chamber. This means that molecules, prior to being detected, may interact with the walls and other inner parts of the setup, which are typically at room temperature. This might affect the measurements as both $\mathrm{H}_{2} \mathrm{O}_{2}$ and $\mathrm{O}_{3}$ can decompose on metal surfaces following general equations, $2 \mathrm{H}_{2} \mathrm{O}_{2} \rightarrow 2 \mathrm{H}_{2} \mathrm{O}+$ $\mathrm{O}_{2}$ and $2 \mathrm{O}_{3} \rightarrow 3 \mathrm{O}_{2}$, further complicating the calculation of precise formation yields.

In this work, we revisit the UV photolysis of pure water and water-rich ice mixtures, utilising a recently developed new diagnostic method that studies UV-irradiated ices in situ and in real time combining laser desorption and mass spectrometry. This allows us to quantitatively trace ice composition, prior to the interaction of the ablated material of the ice with the walls of the setup or the ion optics of the mass spectrometer. The method offers an alternative to spectroscopic techniques to study species with no or weak dipole moments, such as $\mathrm{O}_{2}, \mathrm{~N}_{2}, \mathrm{C}_{2}, \mathrm{~S}_{2}$, etc. This paper is organised as follows: a description of the experimental methods is given in Sect. 2, the results and a follow-up discussion are presented in Sects. 3 and 4, the astrochemical implications are discussed in Sect. 5, and the concluding remarks are summarised in Sect. 6.

\section{Experiments}

The experiments were carried out in the ultra-high vacuum (UHV) system MATRI ${ }^{2}$ CES - Mass Analysis Tool to study Reactions in Interstellar ICES. This section includes a brief description of the setup, a list of completed experiments, and the analysis routine used to quantify the acquired data. A detailed description of the system can be found in Paardekooper et al. (2014).

\subsection{Experimental setup}

MATRI $^{2}$ CES consists of a main chamber connected with a UHV gate valve to a time of flight mass spectrometer (TOF MS) tube. The base pressure in both chambers is in the $\sim 10^{-10}$ mbar range. The main chamber houses a closed-cycle helium cryostat which cools a $1.5 \times 5 \mathrm{~cm}$ gold-coated copper block used as a chemically inert substrate for ice deposition. A thermocouple and a resistive heater are attached to the base of the substrate, which allows us to set its temperature in the $20-300 \mathrm{~K}$ range with a relative precision of $0.25 \mathrm{~K}$. In addition, the cryostat (substrate) is mounted on a two-dimensional translation stage, allowing us to shift its position in the horizontal and vertical directions. Upon reaching the deposition temperature, the vapor and gas samples are admitted through a capillary positioned at 85 degrees with respect to the substrate (front deposition) or pointed away from the substrate (background deposition). Pure water $\left(\mathrm{H}_{2} \mathrm{O}\right.$, milliQ or $\mathrm{H}_{2}{ }^{18} \mathrm{O}$, Sigma-Aldrich, $\left.97 \%{ }^{18} \mathrm{O}\right)$ and 
mixtures with carbon dioxide $\left(\mathrm{CO}_{2}, 99.99 \%\right.$ purity) and molecular oxygen $\left(\mathrm{O}_{2}, 99.99 \%\right.$ purity $)$ are used. Prior to the deposition, liquid samples are purified from the dissolved air contamination by performing three freeze-pump-thaw cycles. A continuous deposition is regulated by a high precision needle valve, which allows the gas-phase sample to go into the main chamber. The growth rate of the ice is determined in advance using $\mathrm{He}-\mathrm{Ne}$ laser (wavelength $632.8 \mathrm{~nm}$ ) interference measurements (Baratta \& Palumbo 1998; Bulak et al. 2020). To calculate the deposition rate for $\mathrm{H}_{2} \mathrm{O}$ (background deposition) and $\mathrm{CO}_{2}$ (front deposition), the refractive indices (1.2, and 1.21) and densities $\left(0.94 \mathrm{~g} \mathrm{~cm}^{-3}, 0.98 \mathrm{~g} \mathrm{~cm}^{-3}\right)$, respectively, are taken from the literature (Kofman et al. 2019; Satorre et al. 2008; Jenniskens et al. 1998). In case of the deposition of $\mathrm{H}_{2} \mathrm{O}: \mathrm{CO}_{2}: \mathrm{O}_{2}$, the mixture was premixed at the intended ratio and deposited through the front deposition capillary following a growth rate calibration for $\mathrm{H}_{2} \mathrm{O}$ and $\mathrm{CO}_{2}$. In all experiments, the deposited ice column density is close to $9 \times 10^{17}$ molecules $\mathrm{cm}^{-2}$ or 90 monolayers ( 1 monolayer $=10^{15}$ molecules $\mathrm{cm}^{-2}$ ) and its uniformity across the substrate is within $\pm 10 \%$. This thickness was chosen to maximise the efficiency of photochemistry in the bulk of the ice. At the same time, a large ice thickness minimises the possible chemical reactions triggered by photoelectrons released from metal substrates upon photolysis. These effects have been restricted to the lower few MLs of the ice (e.g. Jo \& White 1991; Smith et al. 2012) or not observed at all (Chuang et al. 2018).

To simulate the UV field present in the interstellar medium, a microwave discharge hydrogen lamp (MDHL) is used. It is attached to the main chamber via a $\left(\mathrm{MgF}_{2}\right)$ UHV view port directly facing the substrate. The operating conditions of the lamp $\left(\mathrm{H}_{2}\right.$ pressure of 1.44 mbar and $80 \mathrm{~W}$ of applied microwave power at $2.45 \mathrm{GHz}$ ) determine its photon flux and the spectral energy distribution (Ligterink et al. 2015). The corresponding emission spectrum consists of a Lyman- $\alpha(121.6 \mathrm{~nm})$ and molecular $\mathrm{H}_{2}$ emission bands (130-165 nm). The complete spectral energy distribution of the lamp is given in Fig. 4 in Paardekooper et al. (2016). The photon flux was measured with a NIST-calibrated silicone photodiode at the location of the substrate, $14 \mathrm{~cm}$ away from the lamp. The UV photon flux, after the subtraction of the optical emission, amounts to $(2.5 \pm 0.5) \times 10^{14}$ photons $\mathrm{cm}^{-2} \mathrm{~s}^{-1}$.

MATRI $^{2}$ CES uses a unique analytical approach to monitor the ice composition before, during, and after UV irradiation by combining laser desorption and mass spectrometry. This method is known as LDPI TOF MS, laser desorption post-ionisation time of flight mass spectrometry. The probing scheme is initiated by an unfocused laser beam of a Nd:YAG Polaris II (4-5 ns pulse, wavelength of $355 \mathrm{~nm}$ ) which is guided into the main chamber at a 30-degree incidence angle with respect to the substrate (laser shot). Prior to entering the main chamber, the laser beam is trimmed to $1 \mathrm{~mm}$ in diameter which allows us to spatially constrain its impact on the ice. An average pulse energy $\left(65 \mathrm{~mJ} \mathrm{~cm}^{-2}\right)$ is optimised for $90 \mathrm{ML}$ of water ice, as the minimum energy that probes the deposited thickness of the ice. The impact of the laser pulse on the ice triggers a local thermal desorption, creating a plume of species. The composition of the plume represents the composition of the ice at the location of the laser shot (Paardekooper et al. 2014). The plume is ionised via a continuous electron impact ionisation source (mean electron energy of $70 \mathrm{eV}$ ), and after an optimised time delay, a part of it is extracted into the TOF MS chamber using ion optics (plume extraction). In addition to the ionisation event, an electron impact induces the dissociation of species in the plume, which results in a molecule-specific fragmentation pattern (see Sect. 2.2). In the field-free TOF tube, ions with different mass-to-charge ratios $(\mathrm{m} / \mathrm{z})$ are spatially separated and redirected (TOF MS in reflectron mode) into a micro-channel plate detector (MCP). This allows us to record the characteristic flight times for all $\mathrm{m} / \mathrm{z}$ in the plume. This approach has several advantages: TOF MS is a very sensitive detection method, ices are investigated in situ, and signals are recorded in real time. The use of isotopologues offers a further diagnostic tool to identify newly formed species.

To increase the signal-to-noise ratio of the data, the LDPI TOF MS scheme (laser shot, plume extraction, data acquisition) is repeated at a frequency of $5 \mathrm{~Hz}$, simultaneously with the automated translation of the substrate in the vertical direction. This allows us to collect 100 TOF spectra, each corresponding to a non-overlapping spot on the substrate (a column). An average of the TOF spectra in a column is mass calibrated and used to derive the composition of the ice. This scheme is repeated at an updated horizontal position (column) of the substrate, which allows us to probe the same ice while increasing the total UV photon fluence.

The acquisition of multiple data points during an irradiation experiment makes it possible to track the formation and destruction kinetics for the involved species within a single experimental run. This provides an advantage over the regular QMS TPD techniques.

\subsection{Data analysis procedure}

Analysis of the averaged TOF data comprises of three steps: mass calibration, integration of the mass peaks, and a conversion of the signal to an abundance (column density) of a molecule in the ice. Mass calibration of the averaged TOF spectra yields a mass resolution of $\Delta m / m \sim 250$, clearly separating each $m / z$. To calculate the intensity of the peaks, a Pearson IV distribution function is fitted to each feature individually. This function provides an accurate fit to the experimental data as it can account for possible asymmetry within the peak. The errors related to the integration are based on the root mean square (rms) over the residual within one standard deviation from the centre of the peak and are below the uncertainty of the ice thickness determination $( \pm 10 \%)$ (Castellanos et al. 2018).

The calculated mass peak intensities are proportional to a linear combination of species present in the plume (Paardekooper et al. 2014). This allows us to express an integrated mass spectrum, $M_{\mathrm{t}}$, at a given irradiation time, $t$, by

$M_{\mathrm{t}}=\sum_{i=1}^{n} a_{i} \cdot \sigma_{i} \cdot M_{i}$,

where $a_{\mathrm{i}}$ is the molecular abundance of species $i, \sigma_{i}$ is the electron impact ionisation cross-section (at $70 \mathrm{eV}$ ), and $M_{i}$ is the corresponding fragmentation fraction. The following crosssections are used: $2.275\left(\mathrm{H}_{2} \mathrm{O}\right), 2.441\left(\mathrm{O}_{2}\right), 2.516(\mathrm{CO}), 3.521$ $\left(\mathrm{CO}_{2}\right) \AA^{2}$ (Kim et al. 2014). As there is no available data in the literature for the ionisation cross-section of $\mathrm{H}_{2} \mathrm{O}_{2}$, its value is derived empirically. It is based on a linear correlation between the electron impact ionisation cross-section and polarisability $(\alpha)$, represented by a formula $\sigma=1.48 \times \alpha$ (Lampe et al. 1957; Bull et al. 2012). The polarisability of $\mathrm{H}_{2} \mathrm{O}_{2}$ is $1.73 \AA^{3}$ (Johnson 2020), and the derived electron impact ionisation cross-section value for $\mathrm{H}_{2} \mathrm{O}_{2}$ is $2.5 \AA^{2}$. The fragmentation pattern of $\mathrm{H}_{2} \mathrm{O}_{2}$ is adapted from Foner \& Hudson (1962), where the contribution of fragments (peaks other than molecular ion) towards the total yield is $26 \%$. The fragmentation patterns of other molecules relevant for this study are available in the NIST spectral database or previous works, but it should be noted that these are (slightly) 
dependent on the geometry of the experimental system (Kim et al. 2014). The use of these values allows us to solve Eq. (1) for $\mathrm{a}_{\mathrm{i}}$ (arbitrary units), which is proportional to the column density of each species $\left(\mathrm{mol} \mathrm{cm}^{-2}\right), i$.

In the final step of the analysis, the calculated water abundance (in arbitrary units) is set equal to the known thickness of the deposited ice $\left(9 \times 10^{16} \mathrm{~mol} \mathrm{~cm}^{-2}\right.$ or $90 \mathrm{ML}$ assuming $1 \times 10^{15}$ molecules per ML). Subsequently, the signals assigned to other species are converted with respect to the initial column density of water, allowing us to quantify their abundances for different UV fluences. The most significant uncertainty in this conversion is related to the uniformity of the ice thickness $( \pm 10 \%)$, and this value is taken into account when deriving abundances of photoproducts.

To translate the experimental results to environments with different astrochemical conditions, it is useful to describe the efficiency of the photoproduct formation as a molecular yield per amount of energy deposited in the ice. Hence, to calculate the fraction of absorbed photons $\left(I_{\mathrm{abs}}\right)$, the Beer-Lambert absorption law is used:

$I_{\text {abs }}=I_{\text {inc }}\left(1-\mathrm{e}^{-\sigma(\lambda)_{\text {abs }} N}\right)$,

where $I_{\text {inc }}$ is the incident UV photon fluence, $\sigma_{\text {abs }}$ is the average photon absorption cross-section of the ice $\left(\mathrm{H}_{2} \mathrm{O}\right.$ : $3.4 \times 10^{-18} \mathrm{~cm}^{-2}$ ), and $N$ is the ice column density (pure $\mathrm{H}_{2} \mathrm{O}$ experiments: $9 \times 10^{16} \mathrm{~mol} \mathrm{~cm}^{-2}$ ) (Cruz-Diaz et al. 2014a). For calculations related to mixed ices, we used the following absorption cross-section values for $\mathrm{CO}_{2}$ and $\mathrm{O}_{2}: 6.7 \times 10^{-19} \mathrm{~cm}^{-2}$ and $4.8 \times 10^{-18} \mathrm{~cm}^{-2}$ (Cruz-Diaz et al. 2014b). For instance, after a UV irradiation of pure $\mathrm{H}_{2} \mathrm{O}$ ice with $4.8 \times 10^{17}$ photons $\mathrm{cm}^{-2}$ (64 min), $1.3 \times 10^{17}$ photons $\mathrm{cm}^{-2}$ are absorbed: each carry, on average, $9 \mathrm{eV}$ of energy (Ligterink et al. 2015). Thus, after $64 \mathrm{~min}$, a total energy of $1.2 \times 10^{18} \mathrm{eV}$ is deposited in the ice and each water molecule statistically absorbs $1.3 \mathrm{UV}$ photons.

\subsection{Overview of experiments}

In this study, we focus on different ices starting with pure $\mathrm{H}_{2} \mathrm{O}$, the primary constituent of interstellar ices. In a realistic interstellar ice, $\mathrm{H}_{2} \mathrm{O}$ molecules are expected to be mixed with $\mathrm{CO}_{2}$ (Öberg et al. 2007; Pontoppidan et al. 2008). Based on observations, the ratio of $\mathrm{CO}_{2} / \mathrm{H}_{2} \mathrm{O}$ in interstellar ices can vary from 12 to $40 \%$ (Boogert et al. 2015). Only in particular environments (Poteet et al. 2013; Isokoski et al. 2013) have pure $\mathrm{CO}_{2}$ ices been observed. Consequently, we also investigate the photochemistry of three different $\mathrm{H}_{2} \mathrm{O}: \mathrm{CO}_{2}$ ice mixtures. Finally, as $\mathrm{O}_{2}$ may be formed as a side product of (non-energetic) water formation (see e.g. Cuppen et al. 2010; Minissale et al. 2014; Taquet et al. 2016), we also investigated $\mathrm{H}_{2} \mathrm{O}: \mathrm{CO}_{2}$ ices enriched with $\mathrm{O}_{2}$. Once $\mathrm{O}_{2}$ is formed in an ice, it may start contributing to its overall chemical network. However, as the amount of molecular oxygen in the prestellar phase is not known, the recorded data for the $\mathrm{O}_{2-}$ containing ice are presented in the appendix. Table 1 summarises all performed experiments for pure $\mathrm{H}_{2} \mathrm{O}$ ice, $\mathrm{H}_{2} \mathrm{O}: \mathrm{CO}_{2}$ ice mixtures (100:11, 100:22 and 100:44), and $\mathrm{H}_{2} \mathrm{O}: \mathrm{CO}_{2}: \mathrm{O}_{2}(100: 22: 2)$. The assignment of the main photoproducts follows the $\mathrm{H}_{2}{ }^{16} \mathrm{O}$ experiments, and the validity of these results is confirmed using $\mathrm{H}_{2}{ }^{18} \mathrm{O}$.

In addition to the $\mathrm{H}_{2}{ }^{18} \mathrm{O}$ labeled experiments, another control experiment is performed to exclude error-prone results due to $\mathrm{H}_{2} \mathrm{O}$ background contamination. In this experiment, the substrate was exposed to $\mathrm{H}_{2} \mathrm{O}$ vapours above the sublimation point $(190 \mathrm{~K})$, which allows for the characterisation of the water deposited on the walls or ion optics.
Table 1. Summary of the types of performed UV photolysis experiments.

\begin{tabular}{cccc}
\hline \hline $\begin{array}{c}\text { Molecular } \\
\text { composition }\end{array}$ & $\begin{array}{c}\text { Composition } \\
(\%)\end{array}$ & $\begin{array}{c}\text { Temperature } \\
(\mathrm{K})\end{array}$ & $\begin{array}{c}\text { UV photon fluence } \\
\left(10^{18} \text { photons cm } \mathrm{cm}^{-2}\right)\end{array}$ \\
\hline $\mathrm{H}_{2}{ }^{16} \mathrm{O}$ & 100 & 20 & $0-1.8$ \\
$\mathrm{H}_{2}{ }^{18} \mathrm{O}$ & 100 & 20 & $0-1.8$ \\
$\mathrm{H}_{2}{ }^{16} \mathrm{O}: \mathrm{CO}_{2}$ & $100: 11$ & 20 & $0-1.8$ \\
$\mathrm{H}_{2}{ }^{16} \mathrm{O}: \mathrm{CO}_{2}$ & $100: 22$ & 20 & $0-2.9$ \\
$\mathrm{H}_{2}{ }^{16} \mathrm{O}: \mathrm{CO}_{2}$ & $100: 44$ & 20 & $0-2.9$ \\
$\mathrm{H}_{2}{ }^{16} \mathrm{O}: \mathrm{CO}_{2}: \mathrm{O}_{2}$ & $100: 22: 2$ & 20 & $0-2.9$ \\
control $\left(\mathrm{H}_{2} \mathrm{O}\right)$ & 100 & 20,190 & $0-1.2$ \\
\hline
\end{tabular}

Notes. The total thickness used in all ices is $9 \times 10^{16} \mathrm{~mol} \mathrm{~cm}^{-2}$, which accounts for about 90 ML.

The total and incremental UV fluence with which our ice samples are irradiated are representative of the different regions in the ISM. In the centre of a dark cloud, the photon fluence is estimated to be $(3-30) \times 10^{17}$ photons $\mathrm{cm}^{-2}$, considering cosmic ray induced secondary UV flux of $(1-10) \times 10^{3}$ photons $\mathrm{cm}^{-2} \mathrm{~s}^{-1}$ and an average molecular cloud lifetime of up to $10^{7} \mathrm{yr}$ (Shen et al. 2004; Chevance et al. 2020). The UV fluence during a lifetime of a protoplanetary disc was modelled by Drozdovskaya et al. (2014), and, depending on the location within the disc, it varies between $10^{16}$ and $10^{26}$ photons $\mathrm{cm}^{-2}$.

\section{Results}

\subsection{UV photolysis of $\mathrm{H}_{2} \mathrm{O}$ ice}

The mass spectra obtained during the UV photolysis of pure $\mathrm{H}_{2}{ }^{16} \mathrm{O}$ and $\mathrm{H}_{2}{ }^{18} \mathrm{O}$ ices are shown in the upper and lower panels of Fig. 1, respectively. The bottom trace in each panel (black) is a reference mass spectrum that allows us to track changes from the initial composition of the ice. For $\mathrm{H}_{2}{ }^{16} \mathrm{O}$, the unprocessed signature includes peaks at $m / z=16,17,18$, and 19. Peaks at $m / z=18 \times n+1$, where $n=1,2$, and 3 represent protonated water clusters formed in the ablated plume, that is, these are not a reaction product from the UV irradiation, but result from the laser desorption pulse (Gudipati \& Yang 2012).

After UV irradiation of the ice with a fluence of $6 \times 10^{16}$ photons $\mathrm{cm}^{-2}$ (red trace, Fig. 1), new peaks appear at $m / z=32,34$ in the $\mathrm{H}_{2}{ }^{16} \mathrm{O}$ experiment (upper panel) and corresponding features at $m / z=36$ and 38 in the $\mathrm{H}_{2}{ }^{18} \mathrm{O}$ experiment (lower panel). The mass shift of 4 atomic mass units (amu) reveals that the newly formed peaks represent species with two oxygen atoms. Considering the initial composition of the ice (pure $\mathrm{H}_{2}{ }^{16} \mathrm{O}$ and $\mathrm{H}_{2}{ }^{18} \mathrm{O}$ ) and the reference mass spectra of possible photoproducts, the only species explaining these observations are $\mathrm{O}_{2}$ and $\mathrm{H}_{2} \mathrm{O}_{2}$. In addition, the mass peak at $m / z=2$ (for both isotopes) is increased, which must be due to the formation of molecular hydrogen $\left(\mathrm{H}_{2}\right)$ in the ice.

The mass spectra clearly show that upon UV irradiation of water ice, $\mathrm{O}_{2}$ is formed in the solid state. The formation of $\mathrm{H}_{2}$ $(m / z=2)$ and $\mathrm{H}_{2} \mathrm{O}_{2}(m / z=33,34$ in upper panel and $m / z=37$, 38 in lower panel) is observed simultaneously and it is important to note that the contribution of $\mathrm{H}_{2} \mathrm{O}_{2}$ towards mass peaks of $\mathrm{O}_{2}$ due to electron impact ionisation is negligible (Foner \& Hudson 1962). As we probe the molecular plume before its interaction with the metal walls of the setup or its ion optics, the intensity of features representing $\mathrm{O}_{2}{ }^{+}$and $\mathrm{H}_{2} \mathrm{O}_{2}{ }^{+}$provides a firm base to quantify the formation of both photoproducts. This is shown as 

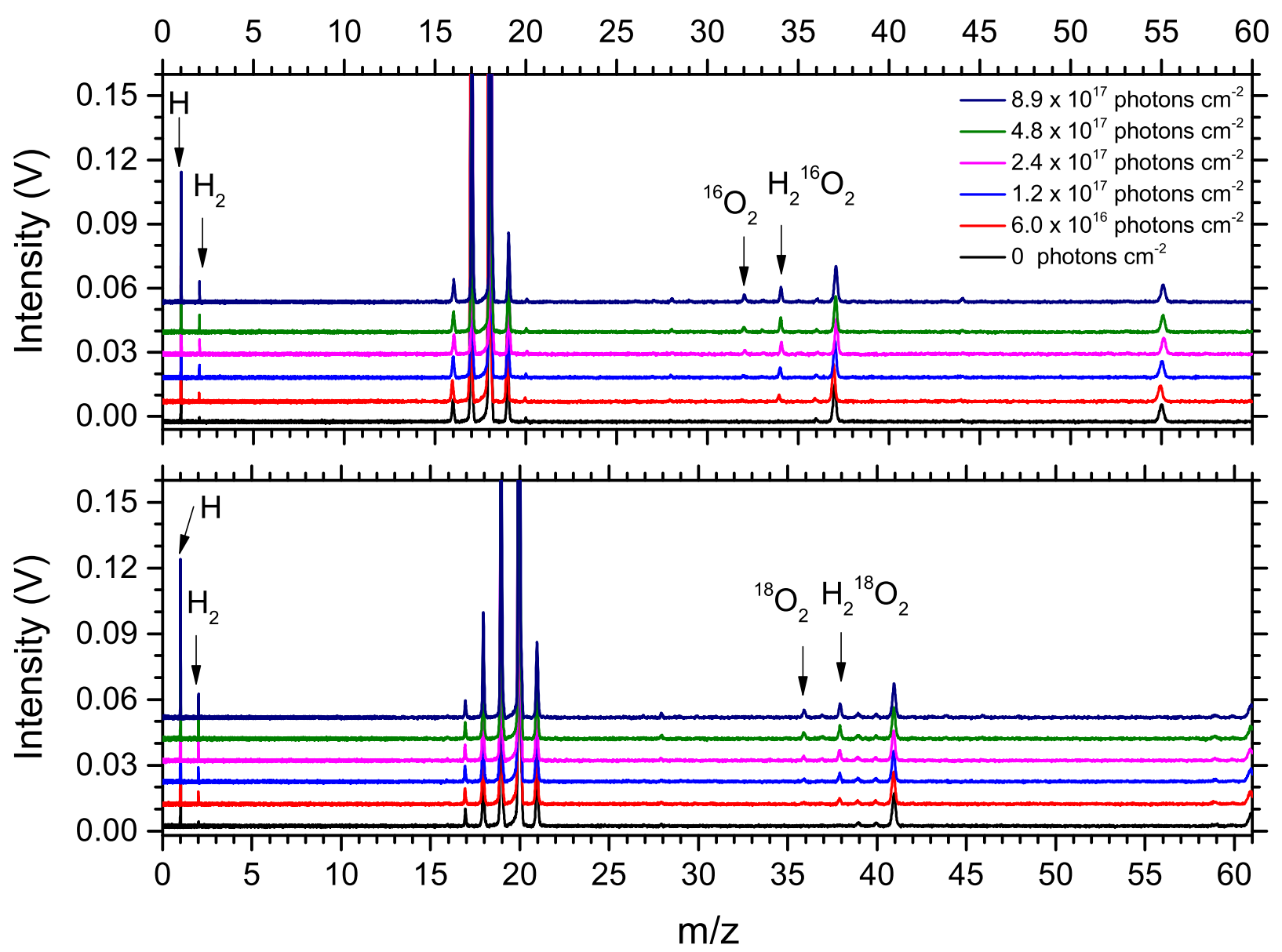

Fig. 1. LDPI TOF MS signals for a UV-irradiated $\mathrm{H}_{2}{ }^{16} \mathrm{O}$ (upper panel) and $\mathrm{H}_{2}{ }^{18} \mathrm{O}$ (lower panel) ice at $20 \mathrm{~K}$ for increasing photon fluence. The lowest trace in each plot shows the signal without UV irradiation. Besides $\mathrm{H}_{2} \mathrm{O}$ and its fragmentation pattern, these spectra reveal the presence of the photolysis products, $\mathrm{H}_{2}, \mathrm{O}_{2}$ and $\mathrm{H}_{2} \mathrm{O}_{2}$. In addition, protonated cluster ions $\left(\mathrm{H}_{2} \mathrm{O}\right)_{n} \mathrm{H}^{+}$are seen to form in the desorption process (see text for details).

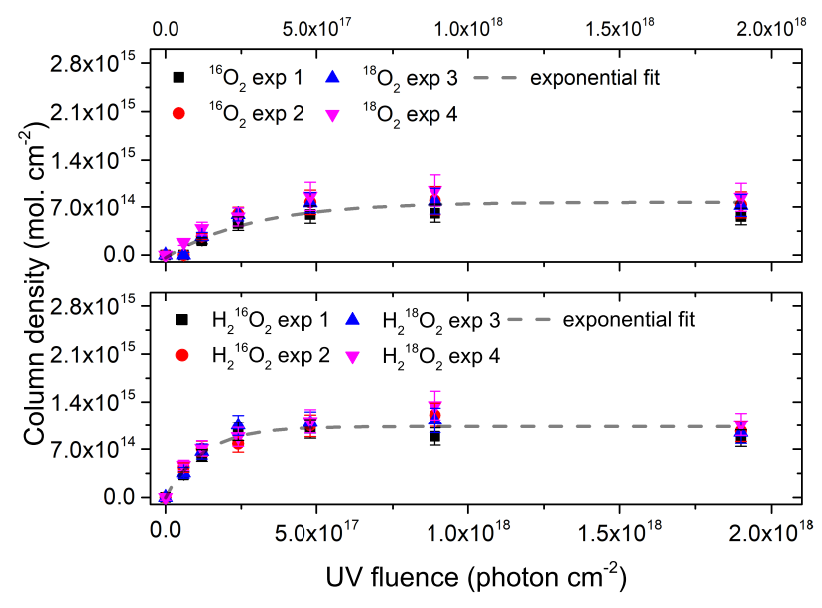

Fig. 2. Molecular abundances of species during the UV photolysis of $\mathrm{H}_{2}{ }^{16} \mathrm{O}$ and $\mathrm{H}_{2}{ }^{18} \mathrm{O}$ ices at $20 \mathrm{~K}$ as function of photon fluence: ${ }^{16} \mathrm{O}_{2},{ }^{18} \mathrm{O}_{2}$ (upper panel) and $\mathrm{H}_{2}{ }^{16} \mathrm{O}_{2}, \mathrm{H}_{2}{ }^{18} \mathrm{O}_{2}$ (lower panel). The results from four separate experiments are shown. The initial ice thickness is $(90 \pm 10)$ ML.

a function of UV fluence in Fig. 2. The abundances are calculated for multiple experiments with both isotopologues following the method described in Sect. 2.2. Subsequently, an exponential function was used to average the photoproduct yields from repeated experiments (for both isotopologues). The formation of $\mathrm{O}_{2}$ reaches its maximum of $(7.6 \pm 2.0) \times 10^{14}$ molecules $\mathrm{cm}^{-2}$ at an incident photon fluence of $8.9 \times 10^{17}$ photons $\mathrm{cm}^{-2}$. For the $\mathrm{O}_{2}$ formation relative to the current $\mathrm{H}_{2} \mathrm{O}$ abundance, we derive a maximum abundance of $\mathrm{O}_{2} / \mathrm{H}_{2} \mathrm{O}$ to be $(0.9 \pm 0.2) \%$. The formation of closely related $\mathrm{H}_{2} \mathrm{O}_{2}$ is saturated at $(1.1 \pm 0.3) \times 10^{15}$ molecules $\mathrm{cm}^{-2}$, which is converted to a relative maximum abundance of $\mathrm{H}_{2} \mathrm{O}_{2} / \mathrm{H}_{2} \mathrm{O}$ equal to $(1.3 \pm 0.3) \%$ (see Appendix A for the water consumption during the experiments in this study).

The observed kinetic curves for $\mathrm{O}_{2}$ and $\mathrm{H}_{2} \mathrm{O}_{2}$ show the formation of both products in the early stages of photolysis. The photoproduct abundances reach a saturation level at a fluence of $(4.8-8.9) \times 10^{17}$ photons $\mathrm{cm}^{-2}$, the exposure dose that marks the equilibrium between formation and destruction routes.

To calculate the product formation efficiency per energy dose deposited in the ice, for each step of the photolysis, only the absorbed photons are considered. For each of the presented UV irradiation doses, the corresponding fraction of incident photons absorbed by the water ice is calculated using Eq. (2) as $(26.0 \pm 6.5) \%$. The largest uncertainty in the fraction of absorbed photons is based on the error bars related to the UV photon flux (25\%). By calculating the yield for each UV dose, an upper limit was determined for the $\mathrm{O}_{2}$ formation in pure $\mathrm{H}_{2} \mathrm{O}$ ice as $(1.3 \pm 0.3) \times 10^{-3} \mathrm{~mol} \mathrm{eV}^{-1}$. A similar calculation was done for $\mathrm{H}_{2} \mathrm{O}_{2}$, which results in a maximum formation yield of $(3.7 \pm 0.9) \times 10^{-3} \mathrm{~mol} \mathrm{eV}^{-1}$. 


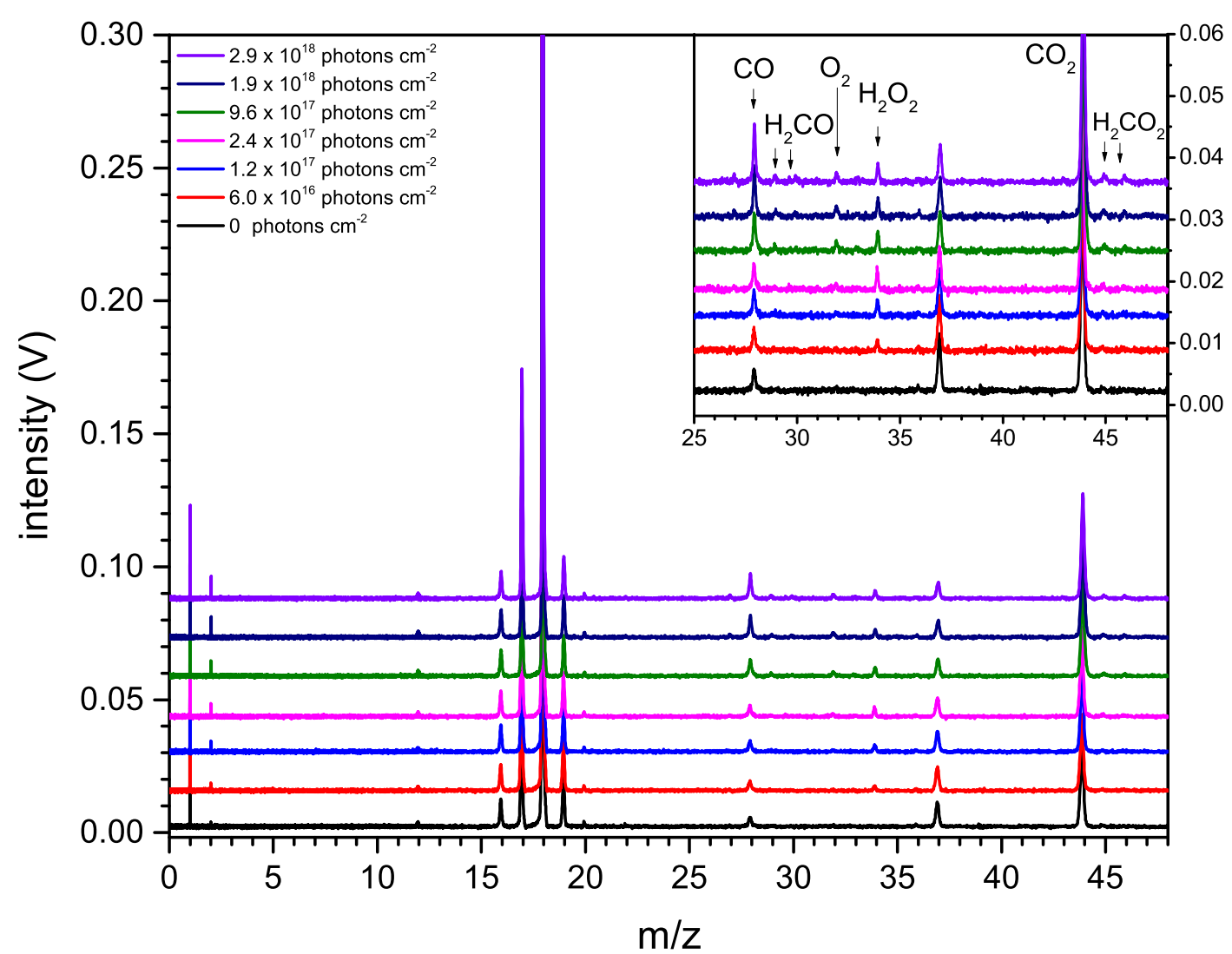

Fig. 3. LDPI TOF MS signals for a UV-irradiated $\mathrm{H}_{2} \mathrm{O}: \mathrm{CO}_{2}$ ice at 100:11 ratio. The lowest trace in each panel shows the signal without UV irradiation. Peaks at $m / z=18 n+1$, where $n=1,2$ represent protonated water clusters formed upon laser desorption of water ice and do not contribute to the chemistry in the ice. The inset is a zoom on the intensity scale for the higher masses.

\subsection{UV photolysis of $\mathrm{H}_{2} \mathrm{O}: \mathrm{CO}_{2}(100: 11,100: 22$, and 100:44)}

The mass spectra obtained during the UV photolysis of the $\mathrm{H}_{2} \mathrm{O}: \mathrm{CO}_{2}=100: 11$ ice mixture are shown in Fig. 3 . The mass spectra for the 100:22 and 100:44 mixtures are presented in Appendix B.

The reference mass spectrum (Fig. 3, black trace), in addition to the previously described water signatures (see Fig. 2), includes the $\mathrm{m} / \mathrm{z}$ values characteristic for $\mathrm{CO}_{2}$, that is, $\mathrm{m} / \mathrm{z}=12,16,28$ and 44. Upon reaching a UV fluence of $6.0 \times 10^{16}$ photons $\mathrm{cm}^{-2}$ (red trace), a number of new $\mathrm{m} / \mathrm{z}$ signals is observed. These signals are representative of the formation of $\mathrm{H}_{2} \mathrm{O}_{2}(m / z=34)$, $\mathrm{H}_{2}(m / z=2)$ and $\mathrm{CO}(m / z=28)$. The formation of $\mathrm{O}_{2}$, at $m / z=32$, is detected simultaneously with $\mathrm{H}_{2} \mathrm{CO}(m / z=29,30)$ and $\mathrm{HCOOH}(m / z=45$ and 46). These assignments are based on the available chemical inventory in the ice and available reference mass spectra. The photoproduct formation is consistent with a decrease in the abundances of precursor species as discussed earlier (see Appendix A).

The mass spectra obtained during the photolysis of $\mathrm{H}_{2} \mathrm{O}: \mathrm{CO}_{2}$ (100:22 and 100:44) ices exhibit the formation of the same photoproducts, but at different relative intensities. This change is correlated with the relative increase in the abundance of $\mathrm{CO}_{2}$ which shifts the elemental balance towards carbon-containing species (CO, Appendix A), and also enhances the total oxygen content.

The abundances of the identified photoproducts are derived for the three mixtures following the method described in Sect. 2.2. The formed product abundances for all mixtures are shown as a function of UV fluence in Fig. 4. The maximum formation yield of $\mathrm{O}_{2}$ reaches $(2.4 \pm 0.6) \times$
$10^{14}$ molecules $\mathrm{cm}^{-2}$ (for the $\mathrm{H}_{2} \mathrm{O}: \mathrm{CO}_{2}=100: 11$ mixture), $(3.4 \pm 0.8) \times 10^{14}$ molecules cm ${ }^{-2}(100: 22)$, and $(5.1 \pm 1.2) \times 10^{14}$ molecules cm $\mathrm{cm}^{-2}(100: 44)$. The formation of $\mathrm{H}_{2} \mathrm{O}_{2}$ peaks at $(8.5 \pm 2.1) \times 10^{14}(100: 11),(3.8 \pm 1.0) \times 10^{14}$ molecules cm $^{-2}$ $(100: 22)$, and $(4.2 \pm 1.0) \times 10^{14}$ molecules $\mathrm{cm}^{-2}$ (100:44). It can be clearly seen that upon an increase in the abundance of $\mathrm{CO}_{2}$ in the mixtures with $\mathrm{H}_{2} \mathrm{O}$, the maximum abundance of formed $\mathrm{O}_{2}$ increases with the amount of $\mathrm{CO}_{2}$ in the ice. An opposite behaviour is seen for $\mathrm{H}_{2} \mathrm{O}_{2}$ formation. Its upper limit abundance decreases, or stays constant, as the initial amount of $\mathrm{CO}_{2}$ in the ice mixture is increased.

In all mixtures, it is found that $\mathrm{H}_{2} \mathrm{O}$ depletes more efficiently, compared to pure $\mathrm{H}_{2} \mathrm{O}$ ice. The formation yields of the observed species are normalised to the current amount of $\mathrm{H}_{2} \mathrm{O}$ for each of the applied UV irradiation doses. Hence, even though the absolute yields of $\mathrm{O}_{2}$ and $\mathrm{H}_{2} \mathrm{O}_{2}$ in mixtures are slightly lower than in pure $\mathrm{H}_{2} \mathrm{O}$ ice photolysis, the relative abundance with respect to $\mathrm{H}_{2} \mathrm{O}$ is increased. For the 100:11 mixture, the relative abundance of $\mathrm{O}_{2} / \mathrm{H}_{2} \mathrm{O}$ and $\mathrm{H}_{2} \mathrm{O}_{2} / \mathrm{H}_{2} \mathrm{O}$ reaches, respectively, $(1.1 \pm 0.3) \%$ and $(1.2 \pm 0.3) \%$. For the 100:22 mixture, a relative abundance of $\mathrm{O}_{2} / \mathrm{H}_{2} \mathrm{O}$ and $\mathrm{H}_{2} \mathrm{O}_{2} / \mathrm{H}_{2} \mathrm{O}$ reaches, respectively, $(1.6 \pm 0.4) \%$ and $(1.8 \pm 0.4) \%$. In the $100: 44$ mixture, relative maximum abundances of $\mathrm{O}_{2} / \mathrm{H}_{2} \mathrm{O}$ and $\mathrm{H}_{2} \mathrm{O}_{2} / \mathrm{H}_{2} \mathrm{O}$ are, respectively, $(1.2 \pm 0.3) \%$ and $(1.1 \pm 0.3) \%$.

To compare the efficiency of photoproduct formation in the $\mathrm{H}_{2} \mathrm{O}: \mathrm{CO}_{2}$ mixtures with the results obtained for the pure $\mathrm{H}_{2} \mathrm{O}$ ice, the peak abundances of products at corresponding UV fluences, have been converted to formation yields per energy dose deposited in the ice. To calculate the fraction of incident photons absorbed by the $\mathrm{H}_{2} \mathrm{O}: \mathrm{CO}_{2}$ ice, we considered the ratio between ice constituents and their respective UV-absorption 

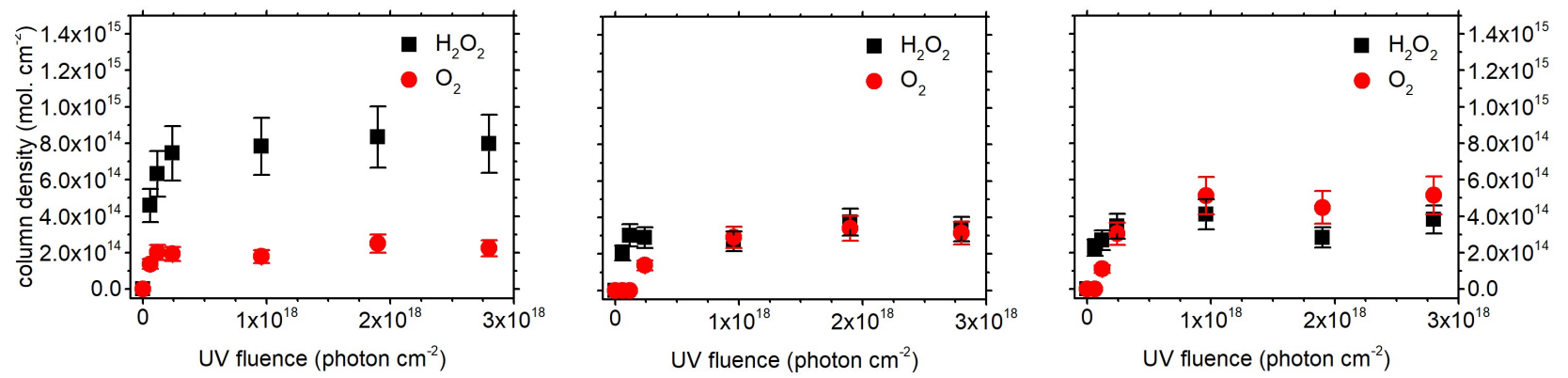

Fig. 4. Absolute molecular abundances of species during the UV photolysis of mixed ices: $\mathrm{H}_{2} \mathrm{O}: \mathrm{CO}_{2}$ ice at 100:11 ratio (left panel), 100:22 (center panel), and 100:44 (right panel). Initial ice thickness is (90 \pm 10$)$ ML.

cross-sections. Consequently, for the $\mathrm{H}_{2} \mathrm{O}: \mathrm{CO}_{2}$ (100:11, $100: 22,100: 44)$ ice mixtures, the fraction of absorbed photons comprise $(24.5 \pm 6.1) \%, \quad(22.5 \pm 5.6) \%$ and $(20.8 \pm 5.2) \%$, respectively. Here, the uncertainty in the absorbed photons is again related to the UV flux throughout the photolysis. This results in the maximum formation yields of $\mathrm{O}_{2}$ equal to $(6.1 \pm 1.8) \times 10^{-4} \mathrm{~mol} \mathrm{eV}^{-1}(100: 11),(9.7 \pm 2.5) \times 10^{-4} \mathrm{~mol} \mathrm{eV}^{-1}$ $(100: 22)$, and $(6.7 \pm 2.1) \times 10^{-4} \mathrm{~mol} \mathrm{eV}^{-1} \quad(100: 44)$. The same calculation for $\mathrm{H}_{2} \mathrm{O}_{2}$ yields $(3.2 \pm 0.7) \times 10^{-3} \mathrm{~mol} \mathrm{eV}^{-1}$ $(100: 11),(1.5 \pm 0.4) \times 10^{-3} \mathrm{~mol} \mathrm{eV}^{-1}(100: 22)$, and $(3.5 \pm 1.0) \times$ $10^{-3} \mathrm{~mol} \mathrm{eV}^{-1}$ (100:44), respectively.

In addition to the mixtures studied above, where $\mathrm{O}_{2}$ is a product of photolysis of $\mathrm{H}_{2} \mathrm{O}: \mathrm{CO}_{2}$, we investigated the photoevolution of an ice, which already includes $\mathrm{O}_{2}$ in the initial composition. The initial amount of $\mathrm{O}_{2}$, at a $2 \%$ level, is based on the results of modelling studies by Taquet et al. (2016). The quantitative analysis is presented in Appendix C.

\section{Discussion}

The results presented in the previous section allow us to discuss (i) the kinetic curves for $\mathrm{O}_{2}$ and $\mathrm{H}_{2} \mathrm{O}_{2}$ during UV irradiation of pure $\mathrm{H}_{2} \mathrm{O}$ ice at $20 \mathrm{~K}$, (ii) the impact of including $\mathrm{CO}_{2}$ in the initial ice composition on (absolute and relative) photoproduct formation yields, and (iii) the presence of $\mathrm{O}_{2}$ in the initial mixture and the evolution of its abundance $\left(\right.$ and $\mathrm{H}_{2} \mathrm{O}_{2}$ ) as a function of UV fluence.

The formation of $\mathrm{O}_{2}, \mathrm{H}_{2} \mathrm{O}_{2}$ in pure $\mathrm{H}_{2} \mathrm{O}$ ice is observed immediately upon the onset of UV photolysis. Its efficiency is low, at a level of $\mathrm{X} / \mathrm{H}_{2} \mathrm{O} \approx 1 \%$. To discuss the possible formation pathways, it is useful to recall the main photodissociation channels of $\mathrm{H}_{2} \mathrm{O}$ (Stief et al. 1975; Harich et al. 2000, 2001; van Harrevelt \& van Hemert 2008; Slanger \& Black 1982):

$\mathrm{H}_{2} \mathrm{O}+h v \rightarrow \mathrm{H}+\mathrm{OH}\left(X^{2} \Pi\right)$,

$\mathrm{H}_{2} \mathrm{O}+h v \rightarrow \mathrm{H}+\mathrm{OH}\left(A^{2} \Sigma^{+}\right)$,

$\mathrm{H}_{2} \mathrm{O}+h v \rightarrow \mathrm{H}_{2}+\mathrm{O}\left({ }^{1} \mathrm{D}\right)$,

$\mathrm{H}_{2} \mathrm{O}+h v \rightarrow \mathrm{O}\left({ }^{3} \mathrm{P}\right)+\mathrm{H}+\mathrm{H}$.

The potential of the newly formed free radicals as precursors for stable molecules is dictated by their abundance, relaxation rates, location within the ice, and diffusion abilities. The abundance of each fragment is given by the wavelength-dependent branching ratios following photodissociation. For $\mathrm{H}_{2} \mathrm{O}$ in the gas-phase, relative quantum yields following UV photodissociation within the used wavelength range consistently point to $\mathrm{OH}$ (in its ground or first excited state) and $\mathrm{H}$ as a dominant channel. This, however, can be different for the solid state (see Öberg et al. 2009a and Lucas et al. 2015 for $\mathrm{CH}_{3} \mathrm{OH}$ ). It is also expected that the total effective photodissociation yield of radicals in the ice will be lower due to the recombination of fragments into the parent species. A detailed investigation of this process is required, but previous experimental studies show that the radical recombination in the water ice can decrease the photodissociation yield by 43-72\%, compared to the gas phase (Mason et al. 2006; Cruz-Diaz et al. 2014a; Kalvāns 2018).

The location of the photodissociation event within the ice is important; combined with the temperature of the ice, it determines the diffusion abilities of the fragments (Andersson et al. 2006; Andersson \& van Dishoeck 2008; Arasa et al. 2010). In particular, if $\mathrm{H}$ and $\mathrm{OH}$ are formed from photodissociation in the top layers of the ice ( $\sim 3 \mathrm{ML})$, both radicals can travel up to a few tens of angstroms within (or on top of) the ice (Andersson \& van Dishoeck 2008). However, the average distance travelled by $\mathrm{H}$ and $\mathrm{OH}$ fragments in the ice is $8 \AA$ and $1 \AA$, respectively. In a realistic scenario, free radicals are formed randomly throughout the ice and can be formed in two different chemical environments: at the ice and vacuum interface on the surface (including pores) and within the ice bulk. In our experiments, the ice thickness (90 ML) was chosen to maximise the contribution of the radicals created in the ice bulk; however, the exact ratio of radicals created in the bulk versus the surface (and pores) is not known. The presence of such a large parameter space significantly complicates the interpretation of our data. Nevertheless, some important observations can be made.

Under the assumption that photodissociation of $\mathrm{H}_{2} \mathrm{O}$ mainly leads to the formation of $\mathrm{H}$ and $\mathrm{OH}$ (in the ground or excited states), the formation of $\mathrm{H}_{2} \mathrm{O}_{2}$ and $\mathrm{H}_{2}$ can be easily accounted for by radical recombination reactions of $\mathrm{OH}+\mathrm{OH}$ and $\mathrm{H}+\mathrm{H}$. However, as formation of $\mathrm{O}_{2}$ can be observed already during the early stages of irradiation, simultaneously with the formation of $\mathrm{H}_{2} \mathrm{O}_{2}$ (see Fig. 2), the involved $\mathrm{O}_{2}$ formation routes must be connected to those of $\mathrm{H}_{2} \mathrm{O}_{2}$ and $\mathrm{H}_{2}$ and involve the direct products of $\mathrm{H}_{2} \mathrm{O}$ photodissociation. Hence, we suggest that $\mathrm{O}$ radicals are present in the ice directly upon water photodissociation (reactions 5 and 6 ). The formation of $\mathrm{O}\left({ }^{1} \mathrm{D}\right)$ via reaction (5) was demonstrated experimentally as a primary process upon photolysis of ASW (UV photolysis with $157 \mathrm{~nm}$ at $90 \mathrm{~K}$ ) by Hama et al. (2009a). This radical can either proceed to react with water via $\mathrm{O}\left({ }^{1} \mathrm{D}\right)+\mathrm{H}_{2} \mathrm{O} \rightarrow 2 \mathrm{OH}$ (Sayós et al. 2001), or relax to its ground state and react with $\mathrm{OH}$ to form $\mathrm{O}_{2}$ via $\mathrm{O}\left({ }^{3} \mathrm{P}\right)+\mathrm{OH} \rightarrow \mathrm{O}_{2}+\mathrm{H}$ (Hama et al. 2010). Channel (6) has not been observed experimentally; however, its contribution is not excluded as the Ly-alpha photons in our spectrum are capable of dissociating water into $\mathrm{O}\left({ }^{3} \mathrm{P}\right)$ (van Harrevelt \& van Hemert 2008). During later stages of photolysis, secondary reaction channels, such as photodissociation of $\mathrm{OH}$ or recombination of 
$\mathrm{OH}$ radicals can contribute towards the formation of $\mathrm{O}\left({ }^{3} \mathrm{P}\right)$, and consequently, $\mathrm{O}_{2}$ (Hama et al. 2009b, 2010).

It is also important to mention that the photodepletion of water is below $\sim 10 \%$. Such inefficient depletion, even for a relatively large number of absorbed photons per $\mathrm{H}_{2} \mathrm{O}$ molecule (i.e. 4-5; see Sect. 3.1), suggests that pure water ice is resilient to UV irradiation, in part due to efficient conversion of the formed products back into $\mathrm{H}_{2} \mathrm{O}$.

The photolysis of $\mathrm{H}_{2} \mathrm{O}: \mathrm{CO}_{2}$ ice mixtures provides additional radical precursors via the following pathways (Slanger \& Black 1978; Kinugawa et al. 2011):

$$
\begin{aligned}
& \mathrm{CO}_{2}+h v \rightarrow \mathrm{O}\left({ }^{3} \mathrm{P}\right)+\mathrm{CO}\left(X^{1} \Sigma^{+}\right), \\
& \mathrm{CO}_{2}+h v \rightarrow \mathrm{O}\left({ }^{1} \mathrm{D}\right)+\mathrm{CO}\left(X^{1} \Sigma^{+}\right) .
\end{aligned}
$$

The addition of $\mathrm{CO}_{2}$ in the ice results in a decreased absolute formation yield of $\mathrm{O}_{2}$ and $\mathrm{H}_{2} \mathrm{O}_{2}$ in comparison to pure $\mathrm{H}_{2} \mathrm{O}$ ice photolysis (see Figs. 2 and 4). This could be due to the lower initial abundance of water $(90 \mathrm{ML})$ and/or $\mathrm{CO}_{2}$ photodissociation products providing reactive radicals leading to competing photoproducts. Indeed, interactions of $\mathrm{OH}$ radicals with $\mathrm{CO}$ (produced by photodissociation of $\mathrm{CO}_{2}$ ) lead to the (re)formation of $\mathrm{CO}_{2}$ (Hama et al. 2010; Ioppolo et al. 2011). Consistently with fewer $\mathrm{OH}$ radicals available, we observe a reduced amount of formed $\mathrm{H}_{2} \mathrm{O}_{2}$. In addition, if $\mathrm{O}$ radicals are present via water photodissociation (see point i) in the discussion), these fragments can also react with $\mathrm{CO}$, to reform $\mathrm{CO}_{2}$, constraining the absolute formation of $\mathrm{O}_{2}$.

Increasing the relative $\mathrm{CO}_{2}$ abundance $\left(\mathrm{H}_{2} \mathrm{O}: \mathrm{CO}_{2}\right.$ from 100:11 to 100:44) leads to a proportional increase in the $\mathrm{O}_{2}$ formation. The maximum formation yield of $\mathrm{O}_{2}$ is increased from $(2.4 \pm 0.6) \times 10^{14}$ molecules $\mathrm{cm}^{-2}$ to $(5.1 \pm 1.2) \times$ $10^{14}$ molecules $\mathrm{cm}^{-2}$ for $\mathrm{H}_{2} \mathrm{O}: \mathrm{CO}_{2}$ mixtures with a ratio of 100:11 and 100:44, respectively (see Fig. 4). This is in line with the increased production of $\mathrm{O}$ atoms, via photodissociation of $\mathrm{CO}_{2}$ in the ice and formation of $\mathrm{O}_{2}$ following $\mathrm{O}+\mathrm{OH}$ and $\mathrm{O}+\mathrm{O}$ interactions. With more initial $\mathrm{CO}_{2}$, the formation of $\mathrm{H}_{2} \mathrm{O}_{2}$ becomes less efficient, which could be simply due to fewer $\mathrm{OH}$ radicals available in the ice and the competitive reaction of $\mathrm{CO}+\mathrm{OH} \rightarrow \mathrm{CO}_{2}$

The absolute yields of $\mathrm{O}_{2}$ and $\mathrm{H}_{2} \mathrm{O}_{2}$ during $\mathrm{UV}$ photolysis of mixed ices $\left(\mathrm{H}_{2} \mathrm{O}: \mathrm{CO}_{2}\right)$ are lower compared to pure $\mathrm{H}_{2} \mathrm{O}$ ice, however, the relative abundances of $\mathrm{O}_{2} / \mathrm{H}_{2} \mathrm{O}$ increase. This is due to a more significant photoconversion of $\mathrm{H}_{2} \mathrm{O}$ molecules to other species.

The analysis of the most complex $\mathrm{H}_{2} \mathrm{O}: \mathrm{CO}_{2}: \mathrm{O}_{2}$ ice mixture provides hints for more efficient formation pathways towards $\mathrm{O}_{2}$ and $\mathrm{H}_{2} \mathrm{O}_{2}$ (see Appendix $\mathrm{C}$ ). In this mixture, in addition to the previously described fragments, $\mathrm{O}$ radicals are available directly upon photodissociation of $\mathrm{O}_{2}$ (Lambert et al. 2004):

$\mathrm{O}_{2}+h v \rightarrow \mathrm{O}\left({ }^{3} \mathrm{P}\right)+\mathrm{O}\left({ }^{3} \mathrm{P}\right)$

$\mathrm{O}_{2}+h v \rightarrow \mathrm{O}\left({ }^{1} \mathrm{D}\right)+\mathrm{O}\left({ }^{3} \mathrm{P}\right)$.

At the early stages of photolysis, the formation efficiency of both $\mathrm{O}_{2}$ and $\mathrm{H}_{2} \mathrm{O}_{2}\left(\mathrm{~mol} \mathrm{eV}^{-1}\right)$ is an order of magnitude higher compared to other mixtures or pure water ice. The interpretation of such a result should be performed carefully, as here a precursor is included that in fact is the reaction product the experiment is aiming at. It is found, however, that the maximum abundance observed during the photolysis cannot be accounted for by the initial $\mathrm{O}_{2}$ injection (Fig. C.2). The increased formation yield hints for additional chemical mechanisms from the pathways discussed above. These are most likely associated with the presence of a highly reactive radical, $O\left({ }^{1} \mathrm{D}\right)$. The increased formation of $\mathrm{O}_{2}$ might indeed be partially due to $\mathrm{O}\left({ }^{1} \mathrm{D}\right)$ radicals produced via the dissociation of $\mathrm{O}_{2}$, reacting with $\mathrm{CO}_{2}, \mathrm{H}_{2} \mathrm{O}$ or their photodissociation products (Wen \& Thiemens 1993; Sayós et al. 2000). A significantly higher abundance (compared to other mixtures) is also observed for $\mathrm{H}_{2} \mathrm{O}_{2}$. This could be due to a barrierless reaction of $\mathrm{O}\left({ }^{1} \mathrm{D}\right)+\mathrm{H}_{2} \mathrm{O} \rightarrow 2 \mathrm{OH}$, which provides precursor species for the typical radical recombination reaction $(\mathrm{OH}+\mathrm{OH})$ leading to $\mathrm{H}_{2} \mathrm{O}_{2}$ (Sayós et al. 2001). It is also found that $\mathrm{H}_{2} \mathrm{O}: \mathrm{CO}_{2}: \mathrm{O}_{2}$ ice mixture is the only ice studied here, where efficient formation of $\mathrm{H}_{2}$ is not observed. This suggests that $\mathrm{H}$ atoms are consumed via reactions with other ice constituents: $\mathrm{CO}, \mathrm{O}, \mathrm{OH}$, or $\mathrm{O}_{2}$.

\section{Astrophysical implications}

The majority of water in the ISM exists in the solid state and is formed via atom addition reactions on the grains in the dense molecular clouds (Lamberts et al. 2013; Linnartz et al. 2015; van Dishoeck et al. 2021). In addition to $\mathrm{H}_{2} \mathrm{O}$ molecules produced by the hydrogenation of accreting $\mathrm{O}$ atoms $(\mathrm{O}+\mathrm{H} \rightarrow \mathrm{OH}$ and $\mathrm{OH}+\mathrm{H} / \mathrm{H}_{2} \rightarrow \mathrm{H}_{2} \mathrm{O}$ ), other simple molecules are formed during this stage that contribute to the bulk of observed $\mathrm{H}_{2} \mathrm{O}$-rich ices. These molecules include $\mathrm{NH}_{3}$ and $\mathrm{CH}_{4}$, produced by the hydrogenation of $\mathrm{N}$ and $\mathrm{C}$ atoms, respectively, as well as $\mathrm{CO}_{2}$, produced through the interaction of accreting $\mathrm{CO}$ molecules with OH radicals (Fedoseev et al. 2015; Qasim et al. 2020; Hama et al. 2010; Ioppolo et al. 2011). Simultaneously, depending on the local physical environment, an $\mathrm{O}_{2}$ ice reservoir can accumulate (Taquet et al. 2016). Towards the end of the accretion stage in a dense molecular cloud, the increase in chemical complexity of the icy mantles is driven by various types of energetic processing (e.g. cosmic rays, X-rays, UV photons). Later, the chemically enriched icy mantles become part of the material from which a young star, its surrounding planets and other celestial bodies, such as comets, are made from. In fact, the transfer of ices from dark clouds to protoplanetary discs and comets was discussed by Taquet et al. (2016), which showed that the chemical composition of the ices along the comet formation sequence is preserved.

To place our experiments in an astronomical context, Fig. 5 (left panel) shows the relative abundance of $\mathrm{O}_{2} / \mathrm{H}_{2} \mathrm{O}$ for the four studied ice compositions: pure $\mathrm{H}_{2} \mathrm{O}$ and $\mathrm{H}_{2} \mathrm{O}: \mathrm{CO}_{2}$ (100:11, $100: 22,100: 44)$. In addition, the abundances detected in the cometary comae of $67 \mathrm{P}(3.1 \pm 1.1) \%)$ and $1 \mathrm{P}(3.7 \pm 1.7) \%$ are marked. In the experiments we show that during the photolysis of pure $\mathrm{H}_{2} \mathrm{O}$ ice, the $\mathrm{O}_{2} / \mathrm{H}_{2} \mathrm{O}$ ratio can increase up to a level $(0.9 \pm 0.2) \%$, roughly three-four times less than the detected abundances in the cometary comea. For ice mixtures more adequately representing icy mantles $\left(\mathrm{H}_{2} \mathrm{O}: \mathrm{CO}_{2}\right)$, the $\mathrm{O}_{2} / \mathrm{H}_{2} \mathrm{O}$ abundance increases with an increasing initial amount of $\mathrm{CO}_{2}$, up to $(1.6 \pm 0.4) \%$ for the $\mathrm{H}_{2} \mathrm{O}: \mathrm{CO}_{2}(100: 22)$ ice. This value is within a of factor 2 in the range of the cometary abundances. It is expected that other abundant constituents of interstellar ices may also have an impact on relative formation of $\mathrm{O}_{2} / \mathrm{H}_{2} \mathrm{O}$. As an example, the presence of $\mathrm{CO}$ can lead to a decrease in the number of available $\mathrm{H}$ atoms in the ice, as its successive hydrogenations lead to efficient formation of $\mathrm{H}_{2} \mathrm{CO}$ and $\mathrm{CH}_{3} \mathrm{OH}$ (Watanabe \& Kouchi 2002). Subsequently, it would inhibit the recombination of water $(\mathrm{OH}+\mathrm{H})$, leaving $\mathrm{OH}$ radicals that could change the $\mathrm{O}_{2} / \mathrm{H}_{2} \mathrm{O}$ ratio. Dedicated astrochemical modelling is needed to understand how these processes combine with each other.

With regard to species that are chemically related, the nondetection of $\mathrm{O}_{3}$ and $\mathrm{HO}_{2}$ in our experiments is consistent with low cometary and ISM measurements. The abundance ratio of $\mathrm{HO}_{2} / \mathrm{O}_{2}$ for both the $67 \mathrm{P}$ and $\rho$ Oph $\mathrm{A}$ is $2 \times 10^{-3}$ 


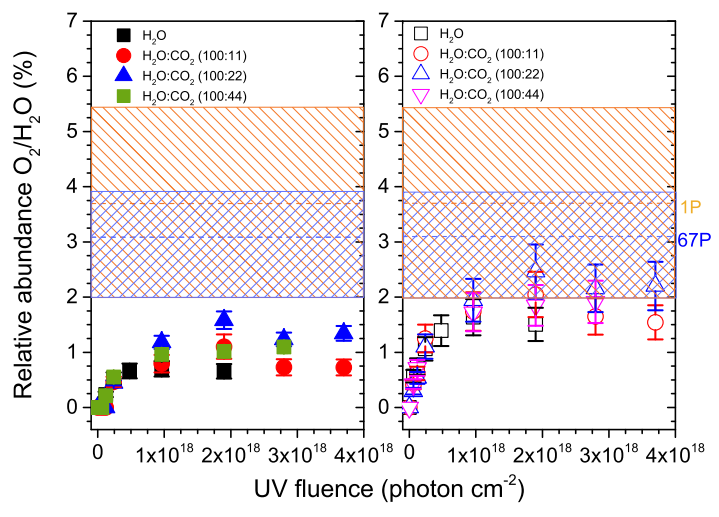

Fig. 5. Striped areas represent relative $\mathrm{O}_{2} / \mathrm{H}_{2} \mathrm{O}$ abundances detected in cometary comae of 67P and 1P from Rubin et al. (2019). The data points represent the laboratory experiments presented here. Left panel: molecular abundance of $\mathrm{O}_{2}$ normalised to the amount of $\mathrm{H}_{2} \mathrm{O}$ at each UV dose for different initial compositions of the ice. Right panel: molecular abundance of $\mathrm{O}_{2}$ enhanced by the decomposition of $\mathrm{H}_{2} \mathrm{O}_{2}$ (see text for details).

(Bieler et al. 2015; Parise et al. 2012), while for $\mathrm{O}_{3}$ there is only an upper limit abundance with respect to $\mathrm{O}_{2}$ at $2 \times 10^{-5}$.

The key discrepancy between our experiments and cometary observations is in the abundance of $\mathrm{H}_{2} \mathrm{O}_{2}$. Its formation during UV photolysis is at a similar level to $\mathrm{O}_{2}$, which is two orders of magnitude above the observed values (Bieler et al. 2015). An explanation for this might be in an efficient dismutation of $\mathrm{H}_{2} \mathrm{O}_{2}$, upon thermal desorption of the water ice as demonstrated by Dulieu et al. (2017). Based on Smith et al. (2011), $\mathrm{H}_{2} \mathrm{O}_{2}$ is expected to be present in the interstellar ices at an abundance of $(9 \pm 4) \%$ with respect to $\mathrm{H}_{2} \mathrm{O}$ and to survive the transfer to the nucleus of the comet. Subsequently, when the comet thermally releases species trapped within the cometary ice, including $\mathrm{H}_{2} \mathrm{O}_{2}$, hydrogen peroxide undergoes a dismutation via $2 \mathrm{H}_{2} \mathrm{O}_{2} \rightarrow 2 \mathrm{H}_{2} \mathrm{O}+\mathrm{O}_{2}$, which is found to produce $\mathrm{O}_{2} / \mathrm{H}_{2} \mathrm{O}$ yields from 1 to $10 \%$ (Dulieu et al. 2017).

Our experiments are set up such that the abundances we record in the gas phase are a direct measure of the ices. The same may not be the case for the gases observed in the comae around comets $1 \mathrm{P}$ and 67P. Therefore, dismutation producing $\mathrm{O}_{2}$ gas from $\mathrm{H}_{2} \mathrm{O}_{2}$ gas could be a contributing factor to the measured abundance of $\mathrm{O}_{2}$ in the comets. If $\mathrm{O}_{2}$ and $\mathrm{H}_{2} \mathrm{O}_{2}$ ices are produced in similar amounts in the cometary ices (similar to the results from our work), and assuming that all $\mathrm{H}_{2} \mathrm{O}_{2}$ is processed into $\mathrm{O}_{2}$ (the $\mathrm{H}_{2} \mathrm{O}_{2}$ abundance is two orders of magnitude below $\mathrm{O}_{2}$ in the comet $67 \mathrm{P}$ ), then the observed abundance of $\mathrm{O}_{2}$ in the cometary comae may be higher than when it was still in the cometary ice (see also Dulieu et al. 2017; Mousis et al. 2016). If we apply this logic to the experimental yields derived here, then the $\mathrm{O}_{2}$ abundances are shifted up by the contribution from the $\mathrm{H}_{2} \mathrm{O}_{2}$ molecules (two $\mathrm{H}_{2} \mathrm{O}_{2}$ molecules are converted into one $\mathrm{O}_{2}$ ). Taking this into account, the experimental values for $\mathrm{O}_{2}$ abundance (in the gas-phase) for a UV fluence of just under $2 \times 10^{18}$ photons $\mathrm{cm}^{-2}$ and an ice mixture of $\mathrm{H}_{2} \mathrm{O}: \mathrm{CO}_{2}(100: 22)$ would fall within the observed abundance limits in both comets (see Fig. 5, right panel).

For the $\mathrm{O}_{2}$-enriched ices, an increase in the $\mathrm{O}_{2} / \mathrm{H}_{2} \mathrm{O}$ ratio is seen for all non-zero UV fluences. It varies between $\sim 3 \%$ and $\sim 7 \%$, with the maximum yield at a relatively low UV fluence (based on Fig. C.2). This corresponds to an increase in $\mathrm{O}_{2} / \mathrm{H}_{2} \mathrm{O}$ abundance by a factor of 1.5-3.5, relatively to the initial $\mathrm{O}_{2}$ amount. Following this, it can be argued that the icy material in comets 1P and 67P could have started out (prior to the pre-solar nebula-stage) with a smaller $\mathrm{O}_{2} / \mathrm{H}_{2} \mathrm{O}$ ice ratio than seen today. Subsequently, during evolution and if subjected to UV photons (or possibly other energetic processing), the initial ratio could have increased by a factor $1.5-3.5$, to explain the ratio that is derived from the Rosina and Giotto missions.

It should be noted that UV photolysis is not the only process that affects the composition of the interstellar ices. Other sources of chemical diversity include high-energy particles, $\mathrm{X}$ rays, cosmic rays (CR) themselves, or CR-triggered avalanches of secondary electrons. In the last two decades, the effects of these processes have been investigated via experiments and astrochemical models (Gomis et al. 2004; Zheng et al. 2006a; Mousis et al. 2016, 2018; Eistrup \& Walsh 2019; Teolis et al. 2017; Shingledecker et al. 2018, 2019; Notsu et al. 2021). These experimental and modelling findings, combined with our novel results, which may (largely) explain the observed cometary $\mathrm{O}_{2} / \mathrm{H}_{2} \mathrm{O}$ ratios, stress the importance of precise chemical modelling. The work presented here now provides explicit values as input parameters.

\section{Conclusions}

LDPI TOF MS was applied to quantify the formation of $\mathrm{O}_{2}$ during UV irradiation of simple interstellar ice analogues $\left(\mathrm{H}_{2} \mathrm{O}\right.$, $\mathrm{H}_{2} \mathrm{O}: \mathrm{CO}_{2}$ and $\left.\mathrm{H}_{2} \mathrm{O}: \mathrm{CO}_{2}: \mathrm{O}_{2}\right)$ at $20 \mathrm{~K}$. The main results are as follows.

1. For a UV photon fluence representative of dense molecular clouds and innermost regions of protoplanetary discs $\left(\sim 10^{18}\right.$ photons $\left.\mathrm{cm}^{-2}\right)$, UV irradiation of porous amorphous $\mathrm{H}_{2} \mathrm{O}$ ice at $20 \mathrm{~K}$ leads to formation of $\mathrm{O}_{2}$ and $\mathrm{H}_{2} \mathrm{O}_{2}$ in the solid state. The maximum abundances of $\left(\mathrm{O}_{2} / \mathrm{H}_{2} \mathrm{O}\right)$ and $\mathrm{H}_{2} \mathrm{O}_{2} / \mathrm{H}_{2} \mathrm{O}$ are equal to $(0.9 \pm 0.2) \%$ and $(1.3 \pm 0.3) \%$, respectively.

2. The mixing of $\mathrm{H}_{2} \mathrm{O}$ with $\mathrm{CO}_{2}$ ice with the ratios 100:11, 100:22, and 100:44 results in an increased relative formation of $\mathrm{O}_{2} / \mathrm{H}_{2} \mathrm{O}$, with a maximum value of $(1.6 \pm 0.4) \%$ for the 100:22 mixture. This also shows that $\mathrm{CO}_{2}$ is involved in the formation of molecular oxygen.

3. The maximum formation efficiency of $\mathrm{O}_{2}$ and $\mathrm{H}_{2} \mathrm{O}_{2}$ per energy unit deposited in the pure $\mathrm{H}_{2} \mathrm{O}$ ice at $20 \mathrm{~K}$ are: $(1.3 \pm 0.3) \times 10^{-3} \mathrm{~mol} \mathrm{eV}^{-1}$ and $(3.7 \pm 1.0) \times 10^{-3} \mathrm{~mol} \mathrm{eV}^{-1}$. These yields are similar for the $\mathrm{H}_{2} \mathrm{O}: \mathrm{CO}_{2}$ mixtures; for $\mathrm{O}_{2}$ it is $(9.7 \pm 0.4) \times 10^{-4} \mathrm{~mol} \mathrm{eV}^{-1}$, and for $\mathrm{H}_{2} \mathrm{O}_{2}$ it is $(3.5 \pm 0.9) \times 10^{-3} \mathrm{~mol} \mathrm{eV}^{-1}$. However, the corresponding maximum photoproduct formation efficiency in the $\mathrm{H}_{2} \mathrm{O}: \mathrm{CO}_{2}: \mathrm{O}_{2}$ mixture are almost an order of magnitude higher; for $\mathrm{O}_{2}$ it is $(1.1 \pm 0.3) \times 10^{-2} \mathrm{~mol} \mathrm{eV}^{-1}$, and for $\mathrm{H}_{2} \mathrm{O}_{2}$ it is $(1.6 \pm 0.4) \times 10^{-2} \mathrm{~mol} \mathrm{eV}^{-1}$. This is without the contribution of the $\mathrm{O}_{2}$ already present in the mixture.

4. The abundances of $\mathrm{O}_{2} / \mathrm{H}_{2} \mathrm{O}$ found in our experiments are sufficient to account for at least part of the observed cometary abundances.

This work demonstrates the potential of MATRI ${ }^{2} \mathrm{CES}$ to investigate the photochemical evolution of interstellar ices analogues, including the infrared-inactive species, upon UV photolysis at low temperature.

Acknowledgements. The authors would like to acknowledge T. Hama for his thorough referee report which improved the quality of this article. M.B. and H.L. acknowledge the European Union (EU) and Horizon 2020 funding awarded under the Marie Skłodowska-Curie action to the EUROPAH consortium (grant number 722346) as well as NOVA 5 funding. Recent support through INTERCAT is acknowledged as well. Additional funding has been realized through a NWO-VICI grant. G.F. also acknowledges financial support from the Russian Ministry of Science and Higher Education via the State Assignment Contract FEUZ-2020-0038. J.T.v.S. is supported by the Dutch Astrochemistry II 
program of the Netherlands Organization for Scientific Research (648.000.025) The authors thank A.G.G.M. Tielens for constructive discussions and remarks.

\section{References}

Andersson, S., \& van Dishoeck, E. F. 2008, A\&A, 491, 907

Andersson, S., Al-Halabi, A., Kroes, G.-J., \& van Dishoeck, E. F. 2006, J. Chem. Phys., 124, 064715

Arasa, C., Andersson, S., Cuppen, H. M., van Dishoeck, E. F., \& Kroes, G. J 2010, J. Chem. Phys., 132, 184510

Bar-Nun, A., Herman, G., Rappaport, M., \& Mekler, Y. 1985, Surf. Sci., 150, 143

Baragiola, R. A., Atteberry, C. L., Dukes, C. A., Famá, M., \& Teolis, B. D. 2002 Nucl. Instr. Methods Phys. R. B, 193, 720

Baratta, G. A., \& Palumbo, M. E. 1998, J. Opt. Soc. Am. A, 15, 3076

Bieler, A., Altwegg, K., Balsiger, H., et al. 2015, Nature, 526, 678

Bockelée-Morvan, D., Lis, D. C., Wink, J. E., et al. 2000, A\&A, 353, 1101

Boogert, A. C. A., Pontoppidan, K. M., Knez, C., et al. 2008, ApJ, 678, 985

Boogert, A. C. A., Gerakines, P. A., \& Whittet, D. C. B. 2015, ARA\&A, 53, 541

Brown, W., Augustyniak, W., Simmons, E., et al. 1982, Nucl. Instr. Methods Phys. R, 198, 1

Bulak, M., Paardekooper, D. M., Fedoseev, G., \& Linnartz, H. 2020, A\&A, 636, A32

Bull, J. N., Harland, P. W., \& Vallance, C. 2012, J. Phys. Chem. A, 116, 767

Castellanos, P., Candian, A., Zhen, J., Linnartz, H., \& Tielens, A. G. G. M. 2018, A\&A, 616, A166

Chevance, M., Kruijssen, J. M. D., Hygate, A. P. S., et al. 2020, MNRAS, 493, 2872

Chuang, K. J., Fedoseev, G., Qasim, D., et al. 2018, A\&A, 617, A87

Cruz-Diaz, G. A., Muñoz Caro, G. M., Chen, Y. J., \& Yih, T. S. 2014a, A\&A, 562, A119

Cruz-Diaz, G. A., Muñoz Caro, G. M., Chen, Y. J., \& Yih, T. S. 2014b, A\&A, 562, A 120

Cruz-Diaz, G. A., Martín-Doménech, R., Moreno, E., Muñoz Caro, G. M., \& Chen, Y.-J. 2018, MNRAS, 474, 3080

Cuppen, H. M., Ioppolo, S., Romanzin, C., \& Linnartz, H. 2010, PCCP, 12, 12077

Drozdovskaya, M. N., Walsh, C., Visser, R., Harsono, D., \& van Dishoeck, E. F. 2014, MNRAS, 445, 913

Dulieu, F., Minissale, M., \& Bockelée-Morvan, D. 2017, A\&A, 597, A56

Eistrup, C., \& Walsh, C. 2019, A\&A, 621, A75

Fedoseev, G., Ioppolo, S., Zhao, D., Lamberts, T., \& Linnartz, H. 2015, MNRAS, 446, 439

Fillion, J.-H., Dupuy, R., Féraud, G., et al. 2021, A\&A, submitted [arXiv:2103.15435]

Foner, S. N., \& Hudson, R. L. 1962, J. Chem. Phys., 36, 2676

Gerakines, P. A., Schutte, W. A., \& Ehrenfreund, P. 1996, A\&A, 312, 289

Gomis, O., Leto, G., \& Strazzulla, G. 2004, A\&A, 420, 405

Gudipati, M. S., \& Yang, R. 2012, ApJ, 756, L24

Hama, T., Yabushita, A., Yokoyama, M., Kawasaki, M., \& Watanabe, N. 2009a J. Chem. Phys., 131, 114510

Hama, T., Yabushita, A., Yokoyama, M., Kawasaki, M., \& Watanabe, N. 2009b, J. Chem. Phys., 131, 114511

Hama, T., Yokoyama, M., Yabushita, A., \& Kawasaki, M. 2010, J. Chem. Phys., 133,104504

Harich, S. A., Hwang, D. W., Yang, X., et al. 2000, J. Chem. Phys., 113, 10073

Harich, S. A., Yang, X. F., Yang, X., van Harrevelt, R., \& van Hemert, M. C. 2001, Phys. Rev. Lett., 87, 263001

Ioppolo, S., Cuppen, H. M., Romanzin, C., van Dishoeck, E. F., \& Linnartz, H. 2008, ApJ, 686, 1474

Ioppolo, S., Cuppen, H. M., Romanzin, C., van Dishoeck, E. F., \& Linnartz, H. 2010, PCCP, 12, 12065

Ioppolo, S., van Boheemen, Y., Cuppen, H. M., van Dishoeck, E. F., \& Linnartz, H. 2011, MNRAS, 413, 2281

Isokoski, K., Poteet, C. A., \& Linnartz, H. 2013, A\&A, 555, A85

Jenniskens, P., Blake, D. F., \& Kouchi, A. 1998, in ASSL, 227, Solar SystemIces, eds. B. Schmitt, C. de Bergh, \& M. Festou (Dordrecht: Springer), 139

Jo, S. K., \& White, J. M. 1991, J. Chem. Phys., 94, 5761

Johnson, R. E. 1991, J. Geophys. Res., 96, 17553

Johnson, III, R. D. 2020, NIST Computational Chemistry Comparison and Benchmark Database; NIST Standard Reference Database Number 101 http://cccbdb.nist.gov

Johnson, R. E., \& Quickenden, T. I. 1997, J. Geophys. Res., 102, 10985

Kalvāns, J. 2018, MNRAS, 478, 2753

Kim, Y. K., Irikura, K. K., Rudd, M. E., \& Ali, M. A. 2014, Electron-Impact Ionization Cross Section for Ionization and Excitation Database (version 3.0)

Kimmel, G. A., \& Orlando, T. M. 1995, Phys. Rev. Lett., 75, 2606

Kinugawa, T., Yabushita, A., Kawasaki, M., Hama, T., \& Watanabe, N. 2011, PCCP, 13, 15785
Kofman, V., He, J., Loes ten Kate, I., \& Linnartz, H. 2019, ApJ, 875, 131

Lambert, H. M., Dixit, A. A., Davis, E. W., \& Houston, P. L. 2004 J. Chem. Phys., 121, 10437

Lamberts, T., Cuppen, H. M., Ioppolo, S., \& Linnartz, H. 2013, PCCP, 15, 8287 Lampe, F., Franklin, J., \& Field, F. 1957, J. Am. Chem. Soc., 79, 6129

Larsson, B., \& Liseau, R. 2017, A\&A, 608, A133

Larsson, B., Liseau, R., Pagani, L., et al. 2007, A\&A, 466, 999

Leto, G., \& Baratta, G. A. 2003, A\&A, 397, 7

Ligterink, N. F. W., Paardekooper, D. M., Chuang, K.-J., et al. 2015, A\&A, 584, A56

Linnartz, H., Ioppolo, S., \& Fedoseev, G. 2015, Int. Rev. Phys. Chem., 34, 205

Liseau, R., Goldsmith, P. F., Larsson, B., et al. 2012, A\&A, 541, A73

Lucas, M., Liu, Y., Bryant, R., Minor, J., \& Zhang, J. 2015, Chem. Phys. Lett., 619,18

Luspay-Kuti, A., Mousis, O., Lunine, J. I., et al. 2018, Space Sci. Rev., 214, 115

Mason, N. J., Dawes, A., Holtom, P. D., et al. 2006, Far. Disc., 133, 311

Minissale, M., Congiu, E., \& Dulieu, F. 2014, J. Chem. Phys., 140, 074705

Miyauchi, N., Hidaka, H., Chigai, T., et al. 2008, Chem. Phys. Lett., 456, 27

Mousis, O., Ronnet, T., Brugger, B., et al. 2016, ApJ, 823, L41

Mousis, O., Ronnet, T., Lunine, J. I., et al. 2018, ApJ, 858, 66

Müller, B., Giuliano, B. M., Bizzocchi, L., Vasyunin, A. I., \& Caselli, P. 2018, A\&A, 620, A46

Notsu, S., van Dishoeck, E. F., Walsh, C., Bosman, A. D., \& Nomura, H. 2021 , A\&A, 650, A180

Oba, Y., Miyauchi, N., Hidaka, H., et al. 2009, ApJ, 701, 464

Öberg, K. I., Fraser, H. J., Boogert, A. C. A., et al. 2007, A\&A, 462, 1187

Öberg, K. I., Garrod, R. T., van Dishoeck, E. F., \& Linnartz, H. 2009a, A\&A, 504,891

Öberg, K. I., Linnartz, H., Visser, R., \& van Dishoeck, E. F. 2009b, ApJ, 693, 1209

Paardekooper, D. M., Bossa, J. B., Isokoski, K., \& Linnartz, H. 2014, Rev. Sci. Instrum., 85, 104501

Paardekooper, D. M., Fedoseev, G., Riedo, A., \& Linnartz, H. 2016, A\&A, 596, A72

Parise, B., Bergman, P., \& Du, F. 2012, A\&A, 541, L11

Pontoppidan, K. M., Boogert, A. C. A., Fraser, H. J., et al. 2008, ApJ, 678, 1005

Poteet, C. A., Pontoppidan, K. M., Megeath, S. T., et al. 2013, ApJ, 766, 117

Qasim, D., Fedoseev, G., Chuang, K. J., et al. 2020, Nat. Astr., 4, 781

Rubin, M., Altwegg, K., van Dishoeck, E. F., \& Schwehm, G. 2015, ApJ, 815, L11

Rubin, M., Altwegg, K., Balsiger, H., et al. 2019, MNRAS, 489, 594

Satorre, M. Á., Domingo, M., Millán, C., et al. 2008, Planet. Space Sci., 56, 1748

Sayós, R., Oliva, C., \& González, M. 2000, J. Chem. Phys., 113, 6736

Sayós, R., Oliva, C., \& González, M. 2001, J. Chem. Phys., 115, 8828

Shen, C. J., Greenberg, J. M., Schutte, W. A., \& van Dishoeck, E. F. 2004, A\&A, 415,203

Shingledecker, C. N., Tennis, J., Le Gal, R., \& Herbst, E. 2018, ApJ, 861, 20

Shingledecker, C. N., Vasyunin, A., Herbst, E., \& Caselli, P. 2019, ApJ, 876, 140

Sieger, M. T., Simpson, W. C., \& Orlando, T. M. 1998, Nature, 394, 554

Slanger, T. G., \& Black, G. 1978, J. Chem. Phys., 68, 1844

Slanger, T. G., \& Black, G. 1982, J. Chem. Phys., 77, 2432

Smith, R. G., Charnley, S. B., Pendleton, Y. J., et al. 2011, ApJ, 743, 131

Smith, R. S., Petrik, N. G., Kimmel, G. A., \& Kay, B. D. 2012, Acc. Chem. R., 45,33

Stief, L. J., Payne, W. A., \& Klemm, R. B. 1975, J. Chem. Phys., 62, 4000

Taquet, V., Furuya, K., Walsh, C., \& van Dishoeck, E. F. 2016, MNRAS, 462, S99

Tielens, A. G. G. M., \& Hagen, W. 1982, A\&A, 114, 245

Teolis, B. D., Plainaki, C., Cassidy, T. A., \& Raut, U. 2017, J. Geophys. Res. (Planets), 122, 1996

Vandenbussche, B., Ehrenfreund, P., Boogert, A. C. A., et al. 1999, A\&A, 346, L57

van Dishoeck, E. F., Kristensen, L. E., Mottram, J. C., et al. 2021, A\&A, 648, A24

van Harrevelt, R., \& van Hemert, M. C. 2008, J. Phys. Chem. A, 112, 3002

Watanabe, N., \& Kouchi, A. 2002, ApJ, 571, L173

Wen, J., \& Thiemens, M. H. 1993, J. Geophys. Res., 98, 12, 801

Westley, M. S., Baragiola, R. A., Johnson, R. E., \& Baratta, G. A. 1995, Nature, 373,405

Whittet, D. C. B., Bode, M. F., Longmore, A. J., et al. 1988, MNRAS, 233 , 321

Woodall, J., Agúndez, M., Markwick-Kemper, A. J., \& Millar, T. J. 2007, A\&A, 466, 1197

Y1ldız, U. A., Acharyya, K., Goldsmith, P. F., et al. 2013, A\&A, 558, A58

Zhen, J., \& Linnartz, H. 2014, MNRAS, 437, 3190

Zheng, W., Jewitt, D., \& Kaiser, R. I. 2006a, ApJ, 639, 534

Zheng, W., Jewitt, D., \& Kaiser, R. I. 2006b, ApJ, 648, 753

Zheng, W., Jewitt, D., \& Kaiser, R. I. 2007, Chem. Phys. Lett., 435, 289 


\section{Appendix A: Abundance of $\mathrm{H}_{2} \mathrm{O}$ and $\mathrm{CO}$ during $\mathrm{UV}$ photolysis}

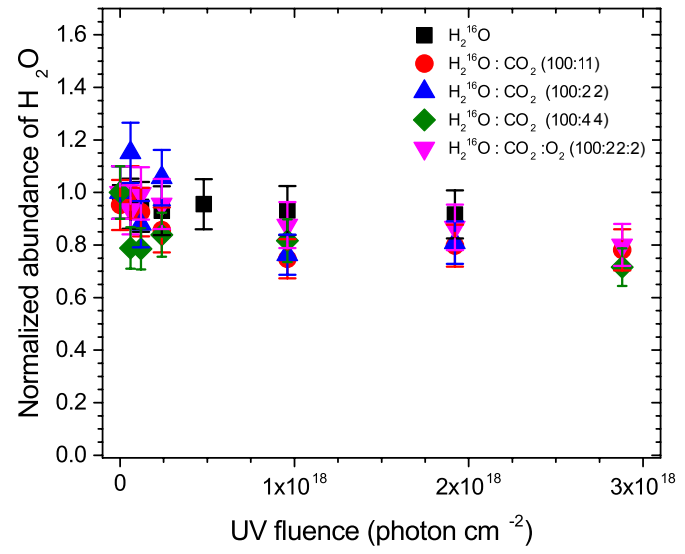

Fig. A.1. Molecular abundance of $\mathrm{H}_{2} \mathrm{O}$ normalised to its initial amount as a function of UV photon fluence for different initial compositions of the ice.

The photodepletion of water was derived for all ices investigated in this study and is shown in Fig. A.1. For the pure $\mathrm{H}_{2} \mathrm{O}$ ice, the depletion was below the uncertainty related to the initial ice thickness; hence, it was calculated based on the abundances of formed photoproducts. The total abundance of $\mathrm{O}_{2}$ and $\mathrm{H}_{2} \mathrm{O}_{2}$ reached $\sim 2 \times 10^{15}$ molecules $\mathrm{cm}^{-2}$. Under the assumption that each of these species requires two $\mathrm{H}_{2} \mathrm{O}$ molecules, the lower limit of water consumption was derived to be $(4.0) \times 10^{15}$ molecules $\mathrm{cm}^{-2}$, which is $4 \%$ of the initial column density of the ice.

The formation of $\mathrm{CO}$ was derived for all mixed ices investigated in this study, shown in Fig. A.2. Towards the end of UV photolysis, $\mathrm{CO}$ was the dominant photoproduct, with a maximum yield in the $\mathrm{H}_{2} \mathrm{O}: \mathrm{CO}_{2}: \mathrm{O}_{2}(100: 22: 2)$ mixture.

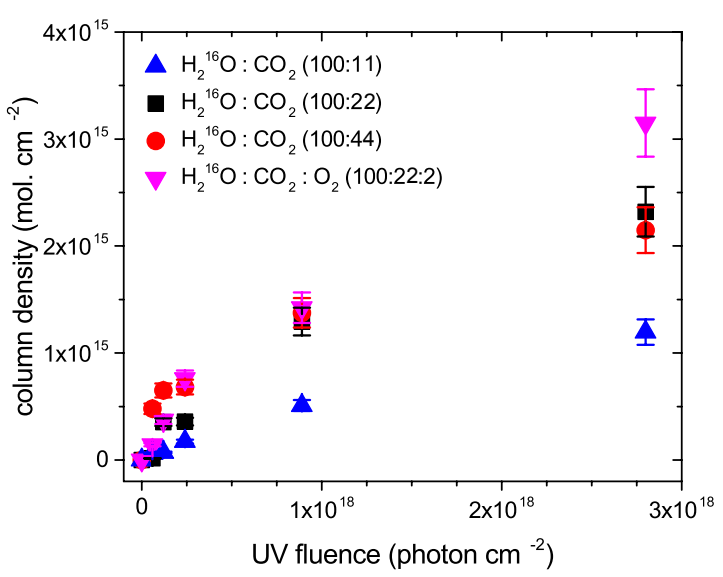

Fig. A.2. Molecular abundance of $\mathrm{CO}$ as a function of UV photon fluence for different initial compositions of the ice.

\section{Appendix B: UV photolysis of $\mathrm{H}_{2} \mathrm{O}: \mathrm{CO}_{2}(100: 22$ and 100:44)}

The mass spectra obtained during the UV photolysis of the $\mathrm{H}_{2} \mathrm{O}: \mathrm{CO}_{2}=100: 22$ and $\mathrm{H}_{2} \mathrm{O}: \mathrm{CO}_{2}=100: 44$ ice mixtures are shown in Fig. B.1 and B.2. 


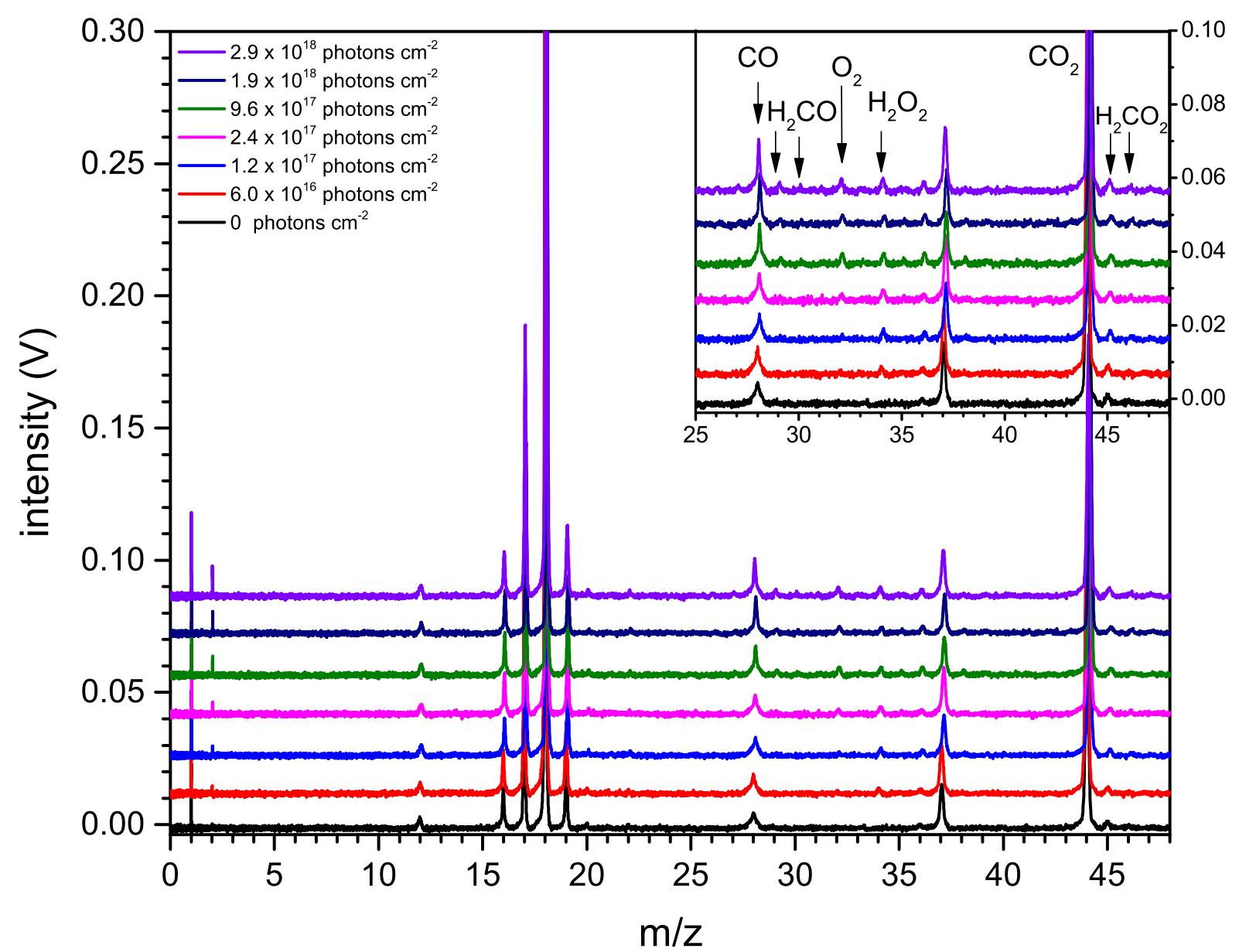

Fig. B.1. LDPI TOF MS signals for a UV-irradiated $\mathrm{H}_{2} \mathrm{O}: \mathrm{CO}_{2}$ ice at 100:22 ratio. The lowest trace in each panel shows the signal without UV irradiation. Peaks at $m / z=18 \cdot \mathrm{n}+1$, where $\mathrm{n}=1,2$ represent protonated water clusters formed upon laser desorption of water ice and do not contribute to the chemistry in the ice. The inset shows a zoomed-in image of the intensity scale for the higher masses. 


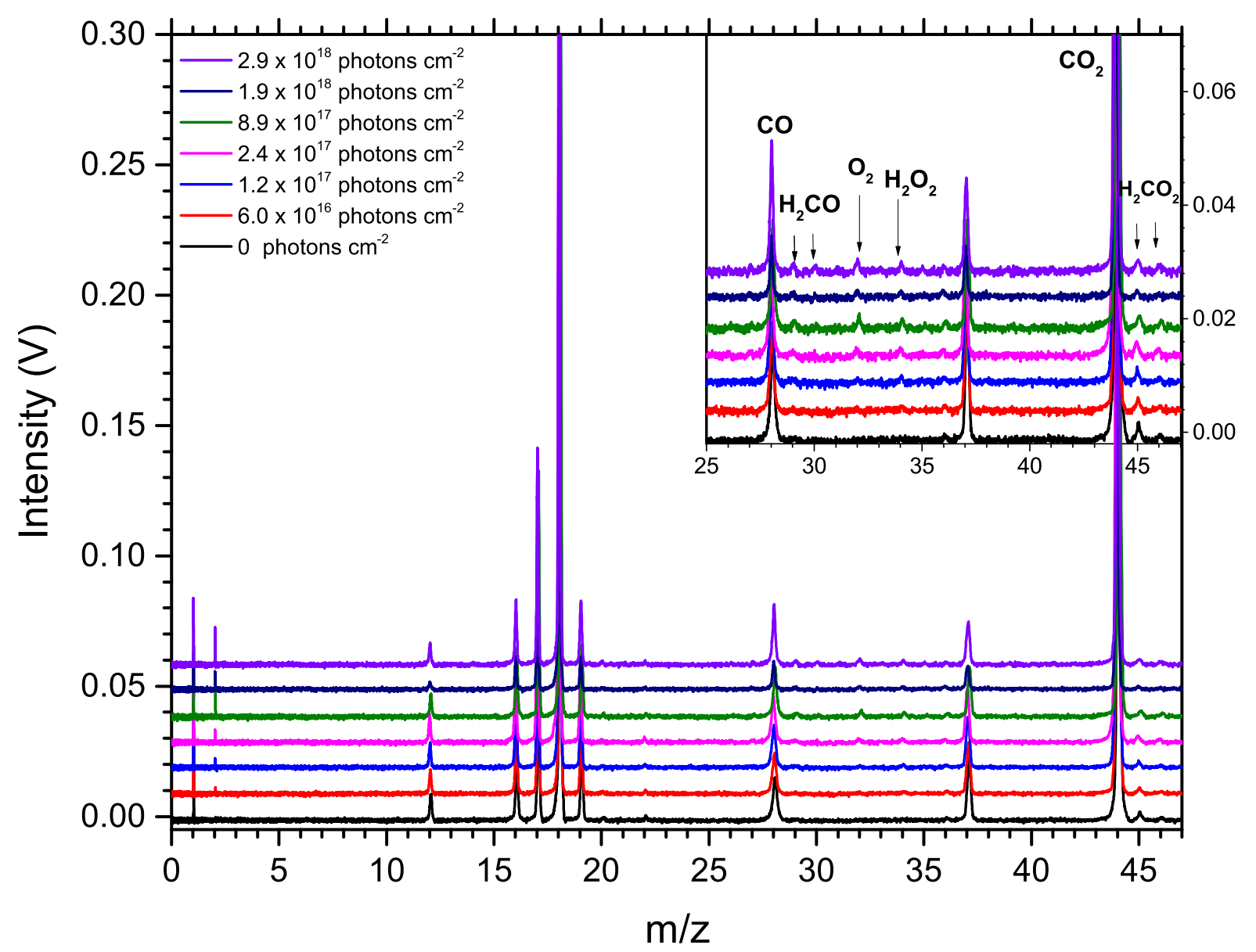

Fig. B.2. LDPI TOF MS signals for a UV-irradiated $\mathrm{H}_{2} \mathrm{O}: \mathrm{CO}_{2}$ ice at 100:44 ratio. The lowest trace in each panel shows the signal without UV irradiation. Peaks at $m / z=18 \cdot \mathrm{n}+1$, where $\mathrm{n}=1,2$ represent protonated water clusters formed upon laser desorption of water ice and do not contribute to the chemistry in the ice. The inset shows a zoomed-in image of the intensity scale for the higher masses.

\section{Appendix C: UV photolysis of $\mathrm{H}_{2} \mathrm{O}: \mathrm{CO}_{2}: \mathrm{O}_{2}$ $(100: 22: 2)$}

The mass spectra resulting from the UV photolysis of an $\mathrm{H}_{2} \mathrm{O}: \mathrm{CO}_{2}: \mathrm{O}_{2}(100: 22: 2)$ mixture are shown in Fig. C.1. The reference mass spectrum (black trace), in addition to the previously described signatures of $\mathrm{H}_{2} \mathrm{O}$ and $\mathrm{CO}_{2}$, also shows the $\mathrm{m} / z$ values corresponding to the initial $\mathrm{O}_{2}$, at $m / z=16$ and 32 .

After UV irradiation of the ice with a fluence of $6 \times 10^{16}$ photons $\mathrm{cm}^{-2}$ (red trace, Fig. C.1), new peaks appear at $m / z=33,34$, and the intensity of features at $m / z=28,29,32$, and 45 increases. This is representative of the formation of $\mathrm{H}_{2} \mathrm{O}_{2}, \mathrm{CO}, \mathrm{H}_{2} \mathrm{CO}, \mathrm{O}_{2}$ and $\mathrm{HCOOH}$. In order to quantify the formation yields of $\mathrm{CO}$ and $\mathrm{O}_{2}$, the signals corresponding to the initial abundances of $\mathrm{CO}_{2}$ (a fragment overlapping with $\mathrm{CO}$ at $m / z=28$ ) and $\mathrm{O}_{2}$ are subtracted, allowing us to trace the contribution from the newly formed molecules. We note that no $\mathrm{H}_{2}$ signal is observed until a high UV fluence of $1.9 \times 10^{18}$ photons $\mathrm{cm}^{-2}$ is reached.

The abundances of identified photoproducts are calculated following the method described in Sect. 2.2. and are presented in Fig. C.2. The $\mathrm{O}_{2}$ abundance increases, reaching $(4.5 \pm 1.1)$ $\times 10^{15}$ molecules $\mathrm{cm}^{-2}$. Upon reaching a UV fluence of $2.4 \times$ $10^{17}$ photons $\mathrm{cm}^{-2}$, the $\mathrm{O}_{2}$ destruction efficiency matches the $\mathrm{O}_{2}$ formation rate and starts to dominate at higher UV fluence. At a fluence of $3.7 \times 10^{18}$ photons $\mathrm{cm}^{-2}$, the $\mathrm{O}_{2}$ abundance continues to decrease, with a final yield below the initial $\mathrm{O}_{2}$ abundance.

The formation of $\mathrm{H}_{2} \mathrm{O}_{2}$ in this mixture follows a trend similar to $\mathrm{O}_{2}$. Its abundance reaches a maximum of $(3.5 \pm 0.9) \times 10^{15}$ molecules $\mathrm{cm}^{-2}$ at $2.4 \times 10^{17}$ photons $\mathrm{cm}^{-2}$. Upon longer irradiation, its abundance decreases to $(1.7 \pm 0.4) \times 10^{15}$ molecules $\mathrm{cm}^{-2}$ at $3.7 \times 10^{18}$ photons $\mathrm{cm}^{-2}$.

The quantified consumption of $\mathrm{H}_{2} \mathrm{O}$ (Appendix A) is used to derive an upper limit on the relative photoproduct formation $\left(\mathrm{X} / \mathrm{H}_{2} \mathrm{O}\right)$ during the photolysis of $\mathrm{H}_{2} \mathrm{O}: \mathrm{CO}_{2}: \mathrm{O}_{2}$ ices. The upper limit of the relative abundance of $\left(\mathrm{O}_{2} / \mathrm{H}_{2} \mathrm{O}\right)$ is calculated to be $(6.9 \pm 1.6) \%$, and the corresponding value for $\left(\mathrm{H}_{2} \mathrm{O}_{2} / \mathrm{H}_{2} \mathrm{O}\right)$ is $(5.4 \pm 1.4) \%$.

The $\mathrm{H}_{2} \mathrm{O}: \mathrm{CO}_{2}: \mathrm{O}_{2}(100: 22: 2)$ ice at each UV dose absorbs $(25.7 \pm 7.2) \%$ of incident photons. Consequently, the formation yields of $\mathrm{O}_{2}$ and $\mathrm{H}_{2} \mathrm{O}_{2}$ reach their maxima equal to $(1.1 \pm 0.3) \times$ $10^{-2} \mathrm{~mol} . \mathrm{eV}^{-1}$ and $(1.6 \pm 0.3) \times 10^{-2} \mathrm{~mol} . \mathrm{eV}^{-1}$, respectively. In comparison to the photolysis of pure water ice and mixtures with $\mathrm{CO}_{2}$, the formation efficiency (in mol. $\mathrm{eV}^{-1}$ ) of both products in this mixture is higher by one order of magnitude. 


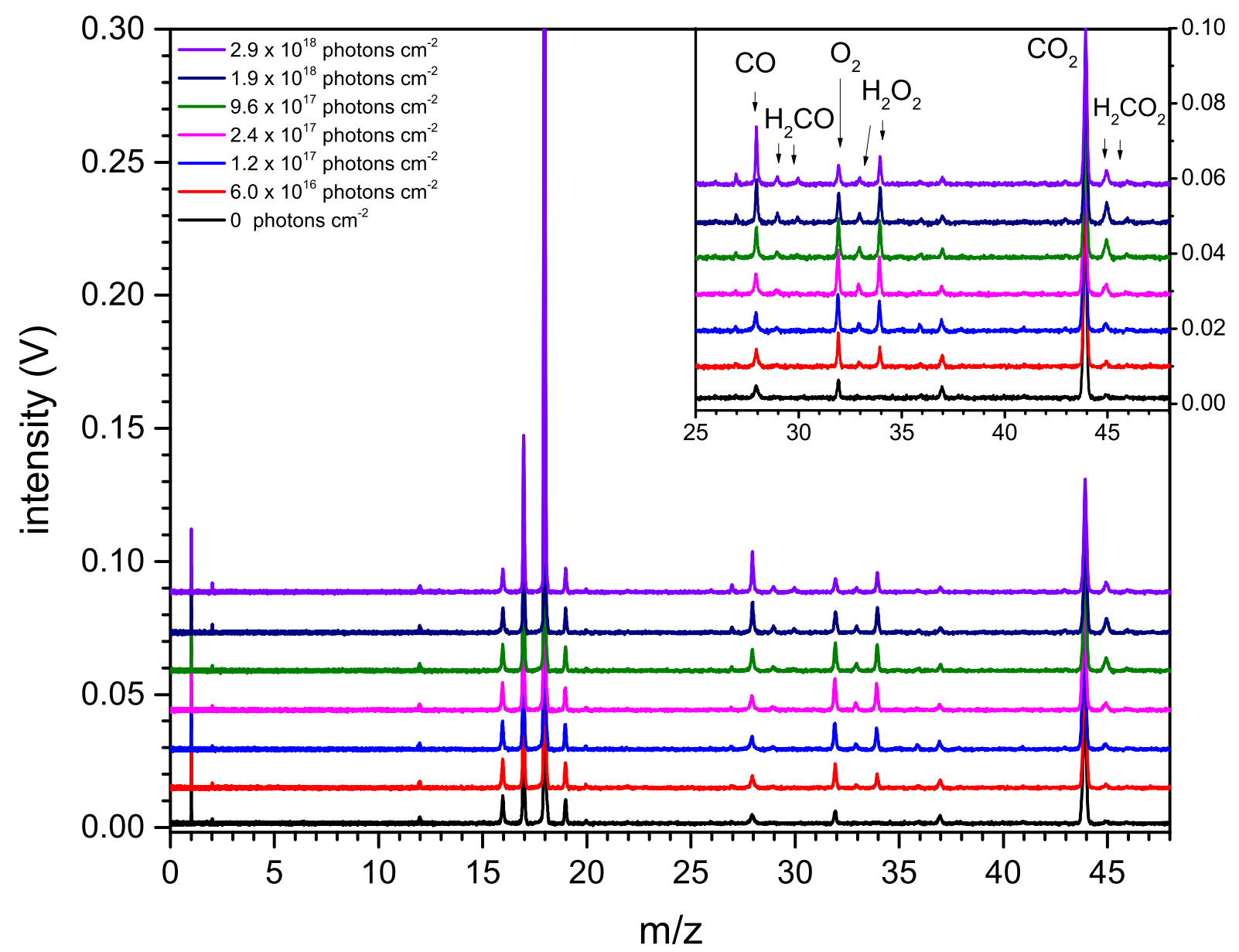

Fig. C.1. LDPI TOF MS signals for a UV-irradiated $\mathrm{H}_{2} \mathrm{O}: \mathrm{CO}_{2}: \mathrm{O}_{2}$ ice at 100:22:2 ratio at $20 \mathrm{~K}$. The lowest graph shows the signal without UV irradiation. The inset shows a zoomed-in image of the intensity scale for the higher masses. Peaks at $m / z=18 \cdot \mathrm{n}+1$, where $\mathrm{n}=1,2 \mathrm{represent}$ protonated water clusters formed upon laser desorption of water ice and do not contribute to the chemistry in the ice.

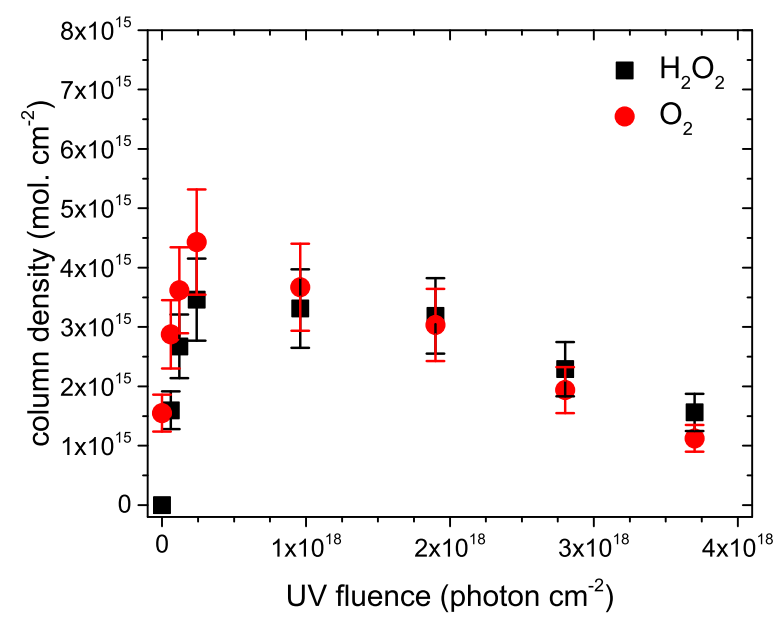

Fig. C.2. Absolute molecular abundances of species during the UV photolysis of mixed ices: $\mathrm{H}_{2} \mathrm{O}: \mathrm{CO}_{2}: \mathrm{O}_{2}$ ice at 100:22:2 ratio. Initial ice thickness is $(90 \pm 10)$ ML. 